Review Article

\title{
Remote sensing-based crop lodging assessment: Current status and perspectives
}

\author{
Sugandh Chauhan ${ }^{\mathrm{a}, *}$, Roshanak Darvishzadeh ${ }^{\mathrm{a}}$, Mirco Boschetti $^{\mathrm{b}}$, Monica Pepe ${ }^{\mathrm{b}}$, Andrew Nelson ${ }^{\mathrm{a}}$ \\ ${ }^{a}$ Faculty of Geo-information Science and Earth Observation (ITC), University of Twente, Enschede 7500AE, the Netherlands \\ ${ }^{\mathrm{b}}$ CNR-IREA, Institute for Electromagnetic Sensing of the Environment, National Research Council, 20133 Milano, Italy
}

\section{A R T I C L E I N F O}

\section{Keywords:}

Crop lodging

Remote sensing

Airborne

Satellite

Risk mapping

Lodging detection

\begin{abstract}
A B S T R A C T
Rapid and quantitative assessment of crop lodging is important for understanding the causes of the phenomena, improving crop management, making better production and supporting loss estimates in general. Accurate information on the location and timing of crop lodging is valuable for farmers, agronomists, insurance loss adjusters, and policymakers. Lodging studies can be performed to assess the impact of lodging events or to model the risk of occurrence, both of which rely on information that can be acquired by field observations, from meteorological data and from remote sensing (RS). While studies applying RS data to assess crop lodging dates back three decades, there has been no comprehensive review of the status, potential, current approaches, and challenges in this domain. In this position paper, we review the trends in field/lab-based and RS-based studies for crop lodging assessment and discuss the strengths and weaknesses of current approaches. Theoretical background on crop lodging is presented, and the scope of RS in assessing plant characteristics associated with lodging is reviewed and discussed. The review focuses on RS-based studies, grouping them according to the platform deployed (i.e., ground-based, airborne and spaceborne), with an emphasis on analyzing the pros and cons of the technology. Finally, the challenges, research gaps, perspectives for future research, and an outlook on new sensors and platforms are presented to provide state-of-the-art and future scenarios of RS in lodging assessment. Our review reveals that the use of RS techniques in crop lodging assessment is still in an experimental stage. However, there is increasing interest within the RS scientific community (based on the increased rate of publications over time) to investigate its use for crop lodging detection and risk mapping. The existing satellitebased lodging assessment studies are very few, and the operational application of the current approaches over large spatial extents seems to be the biggest challenge. We identify opportunities for future studies that can develop quantitative models for estimating lodging severity and mapping lodging risk using RS data.
\end{abstract}

\section{Introduction}

\subsection{Lodging and its impact on agricultural production}

Lodging, which is the displacement of crop stems from their upright position (stem lodging) or failure of root-soil anchorage system (root lodging) (Pinthus, 1974), is a major yield-reducing factor in staple cereal crops such as wheat, rice, barley, maize and oats (Islam et al., 2007; Wu and Ma, 2016). It is induced by strong winds or heavy rain/ hail and is exacerbated by improper crop management practices such as excessive nitrogen applications or high planting density (Quang Duy et al., 2004). Studies conducted by Berry and Spink (2012) and Berry et al. (2013) report that yield losses in cereal crops and oilseed rape in the UK could be as high as $75 \%$, if lodging occurs close to the grain- filling period. In a severe lodging year, such losses are estimated at $£ 105$ and $£ 64$ million for wheat and oilseed rape respectively (Berry, 2013). Lodging also causes several knock-on effects such as deterioration in grain quality, destruction in plant morphology, physiological disruptions, etc. (Norberg et al., 1988; Setter et al., 1997). Therefore, proper monitoring of lodging, its impact and seasonal risk assessment is of interest for farmers, agronomists, insurance loss adjusters, and policymakers.

\subsection{The role of remote sensing}

The past few decades have witnessed considerable growth in the use of sensors on-board Earth-Observation (EO) systems for agricultural monitoring applications. Today, crop biophysical properties such as leaf

\footnotetext{
* Corresponding author.

E-mail addresses: s.chauhan@utwente.nl (S. Chauhan), r.darvish@utwente.nl (R. Darvishzadeh), boschetti.m@irea.cnr.it (M. Boschetti), pepe.m@irea.cnr.it (M. Pepe), a.nelson@utwente.nl (A. Nelson).
} 
area index (LAI) or green area index (GAI) can be estimated globally at high spatial resolution, providing reliable inputs to crop growth models. Remote sensing (RS) estimates of crop lodging are also an important component of crop growth models and can help us make better crop production/loss estimates.

Agronomists and plant physiologists have studied the problem of crop lodging for decades. For example, there are several studies that have developed models to simulate and assess seasonal lodging risk (Baker et al., 1998, 2014; Sposaro et al., 2010) and to understand lodging-related morphological traits (Berry et al., 2002; Islam et al., 2007; Kong et al., 2013). These studies rely on the field or lab-based methods and visual ratings for lodging assessment. Conventionally, visual assessment of lodging is done by assigning a lodging score to a crop, based on the spatial extent and angle of lodging (Fischer and Stapper, 1987). However, such methods are likely to be constrained by limited coverage, high labour consumption, poor accessibility, and unfavourable weather conditions. Even though RS is capable of providing consistent and continuous data in the spatial and temporal domains, there are few examples of its use till date in crop lodging assessment. This is mainly due to the complexity of the lodging process. While it may be straightforward to associate the increase in near-infrared (NIR) reflectance to biomass increment, the assessment of lodging is more complicated. It requires knowledge of local crop management and an understanding of crop biophysical variable dynamics and the physical processes involved in lodging. Given the complexity, our literature search revealed that there are only 22 peer-reviewed articles - published between 1984 and 2018 - that focus on the use of RS to assess lodging damage or its risk. It suggests that the scientific consensus on RS-based lodging assessment methodologies is still evolving.

The way vegetation responds to changing ecological and climatological conditions is reflected by an immediate or slow change in its biophysical and biochemical properties (Hong et al., 2007). The retrieval of such plant properties by RS methods has been well established and documented (Inoue et al., 2016; Chakraborty et al., 2005; Verrelst et al., 2015; Neinavaz et al., 2016; Chauhan et al., 2018; Holzman et al., 2018), and can be extended further to extract lodging-related information. A RS-based approach to study crop lodging requires (i) understanding of specific plant traits, which make a plant susceptible to lodging or can help to assess the occurrence of lodging; and (ii) identification of appropriate modelling approaches. Such information can help predict the occurrence of lodging (risk) and map its severity.

RS-based crop lodging assessment studies have used information from passive and active sensors for lodging detection, i.e. lodged or non-lodged (Liu et al., 2014; Yang et al., 2015) and seasonal lodging risk mapping (Coquil, 2004). These studies have been conducted as improvements to or complements to field/lab-based assessment methods. However, there is no systematic review that relates field/labbased approaches to RS-based methods and characterises the relative strengths, assesses the operational feasibility and identifies potential
RS-based research gaps. This paper addresses the existing gap by exploring the current and potential application of RS for lodging damage and seasonal risk assessment. The objectives of this study are to:

1. Present the contribution of RS within the current framework of field/lab-based crop lodging assessment studies.

2. Present a methodical overview of current approaches for assessing crop lodging and evaluate their strengths and weaknesses in the context of operational applications.

3. Identify the challenges, research gaps and provide perspectives on the potential use of RS for crop lodging assessment research and applications.

\subsection{Review approach}

We browsed scientific citation databases - Google Scholar, Scopus, ISI Web of Science, and Crossref - to search for field/lab-based and RSbased articles on crop lodging, with keywords/expressions such as: crop lodging OR lodging AND husbandry; crop lodging OR lodging risk AND yield loss; remote sensing AND crop lodging OR plant lodging, etc. To refine the search in each category we altered or added more keywords, e.g., we searched for papers focusing on lodging (or its risk) in specific crops such as wheat, barley, and rice, or we substituted "remote sensing" with specific sensor types/names such as Remotely Piloted Aircraft System (RPAS), thermal, multispectral, radar, RADARSAT-2, etc. During the search, we came across very few studies (22) that had used RS technique to assess lodging, which suggests that the use of this technology for crop lodging assessment is still in a nascent stage. To ensure that we covered all the studies, we also searched for the cited references individually.

On the other hand, more than 5000 field/lab-based studies were retrieved based on the set criteria ("crop lodging" OR "lodging risk" AND "husbandry"; "crop lodging" OR "lodging risk" AND "yield loss"). We focus on significant peer-reviewed articles (field/lab-based) on lodging published post-1951 since they have formed an important basis in the understanding of lodging phenomenon. We further pruned the number of field/lab-based studies (to 49) to include modelling or observational studies where RS can have a contribution. The descriptive statistics are derived from a set of 71 studies (field/lab-based - 49, RSbased - 22). Fig. 1 illustrates the trend of field/lab-based and RS-based publications over the past 68 years.

While the focus was to examine progress made in the RS-based assessment of crop lodging and to explore future potential areas, most RSbased studies have built upon numerous field/lab-based experiments, hence their inclusion here. The RS-based studies have mainly highlighted the application of RS for lodging detection in cereal crops (Ogden et al., 2002; Liu et al., 2011; Yang et al., 2017; Zhao et al., 2017) and only a few have investigated the complex interactions between environmental and crop management factors to map (or predict) the risk of lodging (Coquil, 2004).

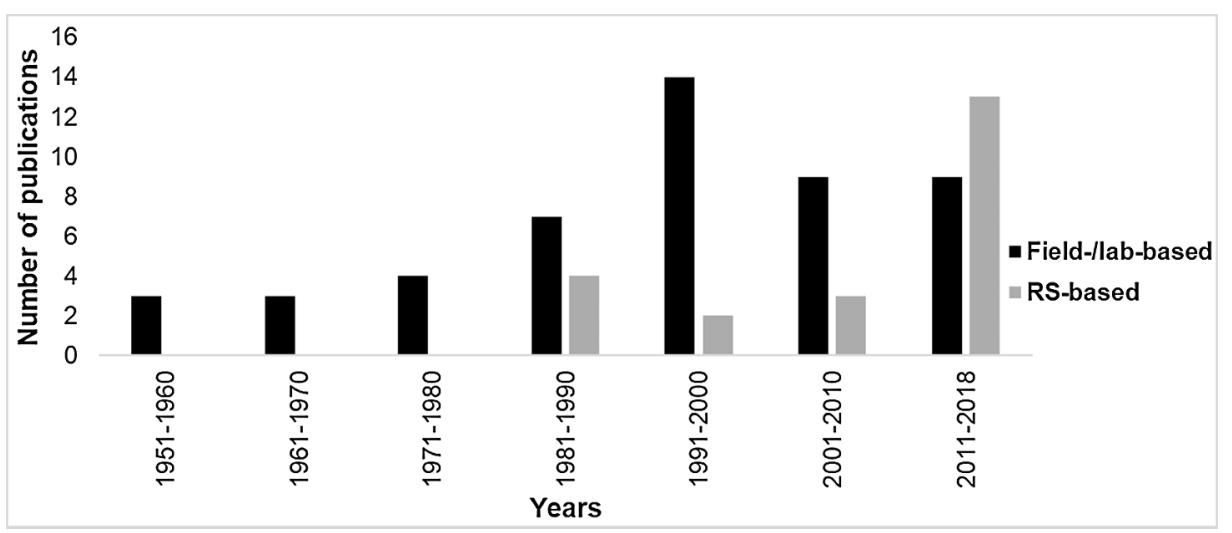

Fig. 1. Number of selected peer-reviewed publications on lodging assessment within the last 68 years. The figure synthesizes the publications retrieved using controlled searches on Crossref, ISI Web of Science, Scopus, and Google Scholar databases. These publications include significant lodging studies that have formed a basis of current lodging research and are important from an RS perspective. These studies are published as complete research articles in peer-reviewed journals or as book chapters or in conference proceedings between 1951 and 2018 . 
The remainder of the paper is structured as follows: Section 2 provides a theoretical background on lodging and briefly discusses the scope of RS within the current framework of field/lab-based studies for crop lodging assessment. The review of these studies aims to understand: (i) the mechanics and factors that cause lodging; (ii) lodginginduced grain yield losses; and (iii) methods/models for crop lodging assessment. Section 3 gives an overview of the status of RS-based crop lodging assessment at different scales and a variety of methods for assessing lodging. The advantages, drawbacks, and potential of each method are also highlighted. Section 4 discusses the challenges of RSbased crop lodging assessment. In Section 5, we examine the research gaps in existing approaches and provide recommendations to undertake future studies. An outlook on the new and upcoming sensors/platforms having a high potential for lodging assessment is presented in Section 6, and the main findings are concluded in the final section.

\section{Theoretical background and scope of RS in lodging assessment}

\subsection{Background and mechanics of lodging}

From a mechanical perspective, the susceptibility of a crop to lodge depends on three factors: (i) the intensity of forces that it is subjected to (such as wind-induced forces) (Pinthus, 1974); (ii) bending strength of the stem and its resistance to buckle (Neenan and Spencer-Smith, 1975); and (iii) the anchorage strength of the root system (Crook and Ennos, 1993). The cultivar, environment, management practices and their complex interactions, strongly influence these factors due to their effects on the crop structure (Sylvester-Bradley and Scott, 1990).

The bending strength of a stem can be quantified by the amount of force needed to break it and is an essential determinant of lodging resistance. Baker (1995) expressed this force as wind-induced base bending moment (leverage force) and illustrated its significance in comprehending the mechanics of stem (Fig. 2b) and root (Fig. 2c) lodging in crops. Crook and Ennos $(1994,1995)$ approximated these wind-induced forces into a crop self-weight moment. Crop self-weight moment is a moment induced at the plant base by the weight of the aerial parts of the plant (such as leaves, head, and stem). It is governed by the plant's height at the centre of gravity, biomass distribution of the tillers, in addition to the crop angle of inclination (illustrated in Fig. 2a). Timely and quantitative measurement of the variation in cropself weight moment (or its determinants such as wet biomass) can help assign safety factors to reduce stem/root lodging and more importantly, can indicate the risk of lodging in future. A large body of literature spanning almost five decades has shown that RS technology has the potential to study the complex interactions in the crop canopy by providing detailed spatio-temporal information

on plant response to the local environment and management practices (Asrar et al., 1985; Jackson, 1986; Pettorelli et al., 2005; Cleland et al., 2007; Lemaire et al., 2008; Jones, 2013).

\subsection{Factors affecting crop lodging}

Lodging risk or standing power of a crop is altered by the genetic, crop management and environmental factors as shown in Fig. 3 (Hanley et al., 1961; Berry et al., 2000). The effect of these factors on lodging is difficult to quantify due to the complexity of the lodging process. According to the practical guidelines issued by the Agriculture and Horticulture Development Board (AHDB, 2005), lodging risk is scored on a scale of 1-9 (a higher score means higher resistance to lodging). To assess a variety's susceptibility of lodging, the varietal lodging score (determined through variety trials) is adjusted for the effect of windspeed, rainfall, LAI/GAI, crop nitrogen content, soil nitrogen supply, sowing date, and plant population density.

Weather is an important aspect affecting lodging. Even $6-11 \mathrm{~mm}$ rain in a day can cause root failure by decreasing the soil strength, thereby increasing the risk of root lodging (AHDB, 2005). The study by Sylvester-Bradley and Scott (1990) suggests that prolonged rainfall can also increase the crop self-weight moment on the stem base. Heavy rain, when accompanied by strong winds, can significantly increase the lodging risk too (Niu et al., 2016).

Apart from environmental factors, the crop management plan can be designed such that it minimises the lodging risk. Sowing date, for instance, can affect the risk of lodging in winter wheat (Green and Ivins, 1985). Early sowing is known to increase crop lodging risk as it increases the residual soil nitrogen uptake efficiency, which results in profuse vegetative growth (Kirby et al., 1985; Fischer and Stapper,

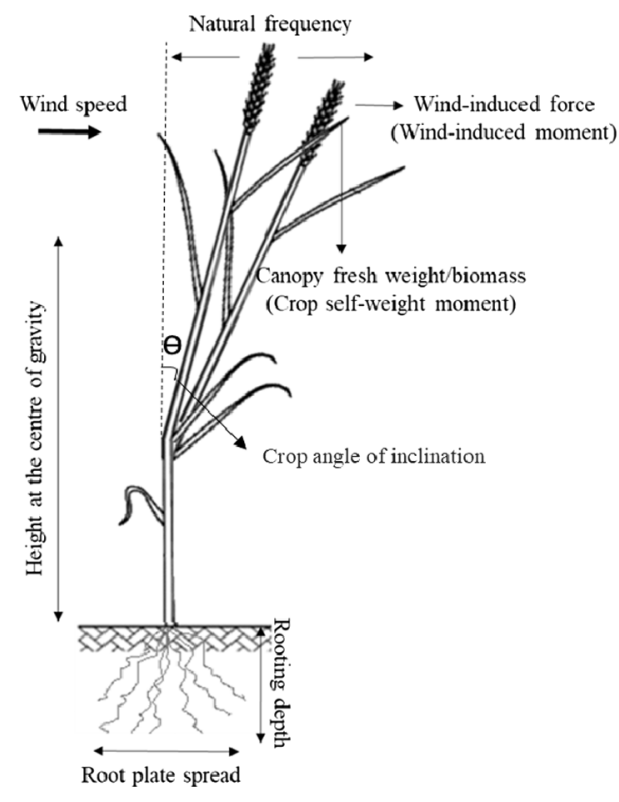

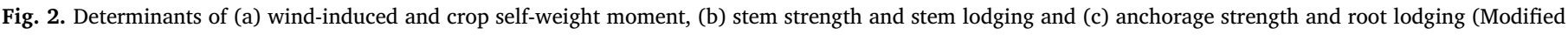
after Berry et al. (2002)).
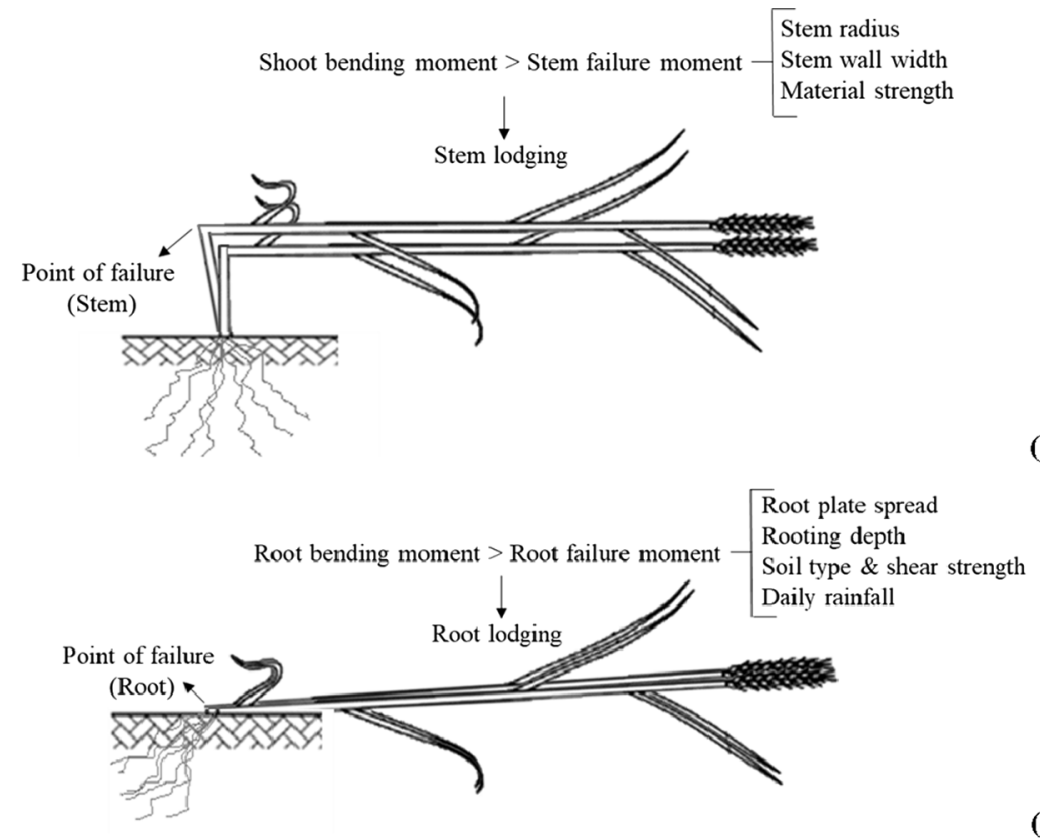

(a) 

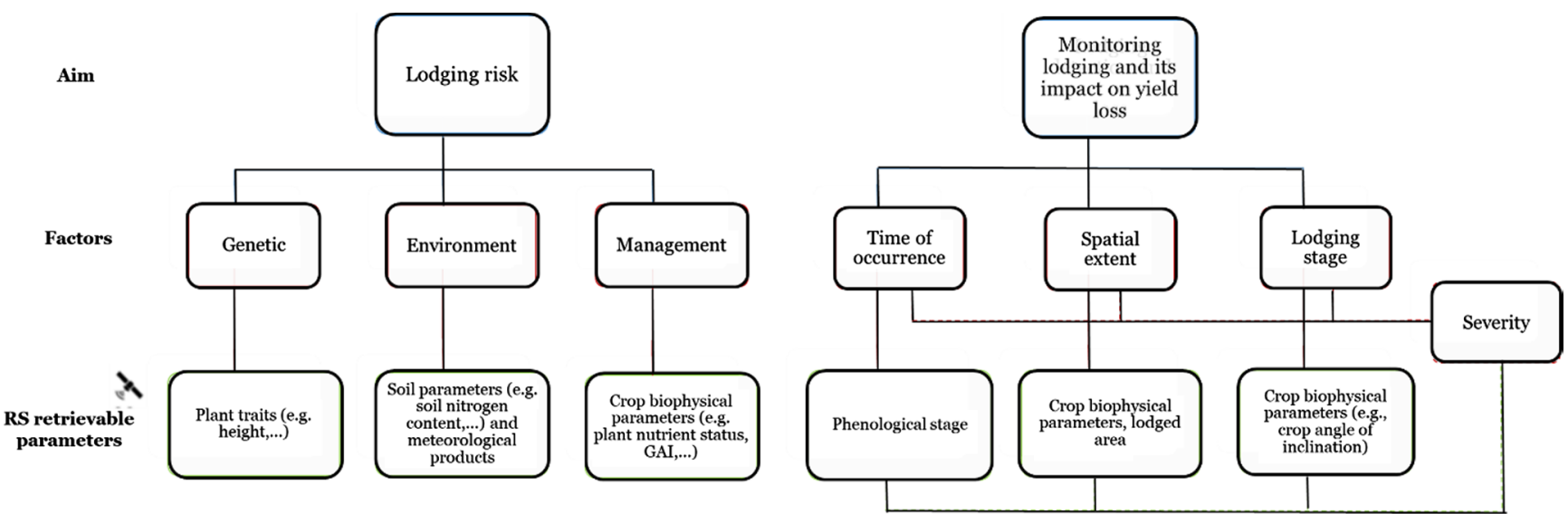

Fig. 3. Summary of important factors related to lodging (seasonal risk assessment, monitoring lodging and its impact on yield loss) and potential contribution of RS.

1987; Milford et al., 1993; Spink et al., 2000). RS can provide reliable methods to monitor plant phenology and delineate spatio-temporal, phenological patterns across large areas in a timely and accurate way (Chu et al., 2016; Boschetti et al., 2017; Manfron et al., 2017). While numerous methods have been proposed to detect the timing of vegetation green-up, maturity, senescence, and dormancy (e.g., Zhang et al., 2003; Funk and Budde, 2009), only a few have related phenological information derived from RS time series to determine actual sowing dates (e.g. Marinho et al., 2014; Jain et al., 2016; Boschetti et al., 2017; Manfron et al., 2017).

Lodging due to high plant population density is also prevalent in many crops such as wheat (Webster and Jackson, 1993), corn (Sangoi et al., 2002; Van Roekel and Coulter, 2011) and barley (Kirby, 1967). High seed rates lead to dense plant tillering and competition for limited resources (nutrients, space, etc.). According to AHDB guidelines (AHDB, 2005), an increase of 50 plants $/ \mathrm{m}^{2}$ in winter wheat can lower the root and stem lodging score by 1 and 0.5 respectively. High plant nitrogen and soil nitrogen supply can also increase lodging in cereals by either promoting vegetative growth (i.e., biomass) or by increasing stem height and thereby the crop self-weight moment (El Debaby et al., 1994, Chalmers et al., 1998; Tripathi et al., 2003). Accurate measurement of plant population density and nitrogen content during the growing season is not the only key to targeted application of resources (such as fertilisers or plant growth regulators) but also for mapping seasonal lodging risk. A number of studies have shown that RS signal (e.g., reflectance or backscatter) is a potential source for estimating plant population density (Patel et al., 2006; Thorp et al., 2007; Bai et al., 2010) and crop/soil nitrogen status (He et al., 2016; Sorenson et al., 2017).

Structural crop parameters, such as crop height, can also affect the lodging resistance of a variety and have been a central focus of seasonal crop lodging risk management (Pinthus, 1974). In the event of lodging, the plant structure is destroyed such that the stem is inclined at a certain angle, and plant height is reduced (Setter et al., 1997; Murakami et al., 2012; Zhu et al., 2016). Setter et al. (1997) reported a reduction of $75 \%$ in rice canopy height under lodged conditions, which consequently lowered the photosynthesis rate by $60-80 \%$ relative to nonlodged rice. A rapid, continuous, and in-season availability of crop height data is essential for developing lodging classification models and seasonal risk mapping applications. Structure-from-Motion (SfM) photogrammetry using high-resolution RPAS data (Holman et al., 2016), crop surface models derived from LiDAR data (Eitel et al., 2016) and polarimetric-interferometric capabilities of SAR data (Erten et al., 2016) have been applied successfully to estimate crop height through the growing season. The measurement of LAI or GAI at the beginning of stem elongation (GS 30-31, according to the Zadoks et al. (1974) growth scale), together with ancillary information on the varietal lodging resistance score and the yield potential, can also enable lodging risk prediction and formulate subsequent plant growth regulator (PGR) programme (BASF, 2011). Using RS, LAI/GAI products can be produced at local, regional and global scales. For instance, LAI/GAI has been derived from high spatial resolution $(10-30 \mathrm{~m})$ data such as MSI and ETM + /OLI-TIRS on-board Sentinel-2 and Landsat respectively (Fang et al., 2003; Campos-Taberner et al., 2016), as well as from coarse to moderate resolution data $(1 \mathrm{~km})$ such as MODIS, SPOT/VEGETATION, AVHRR and PROBA-V sensors (Gao et al., 2008; Baret et al., 2013).

\subsection{Crop yield response to lodging}

The response of grain yield to lodging has been explored in a large number of studies, but only at field or lab scale (Sisler and Olsen, 1951; Lee and Rush, 1983; Baylis and Wright, 1990; Easson et al., 1993; Lang et al., 2012; Acreche and Slafer, 2011; Mi et al., 2011). The outcome of these studies indicates that the spatial extent of lodging, its stage (crop angle of inclination) and the time of its occurrence rule the severity of lodging and, in turn, affect the extent of yield loss (Fig. 3). A crop with a high crop angle, lodged on a large surface area and close to the grainfilling stage, depicts the most severe form of lodging (Laude and Pauli, 1956; Stanca et al., 1979; Caldicott and Nuttall, 1979; Berry and Spink, 2012). Determination of lodging severity has long been pursued via conventional field-based methods (Fischer and Stapper, 1987; PiñeraChavez et al., 2016). RS has demonstrated to be a superior alternative for measuring 3D vegetation structure across different scales (e.g., Gao et al., 2013). While several studies have assimilated RS data into crop models to improve crop yields estimates (Fang et al., 2008; Dente et al., 2008), further work is required to incorporate lodging severity into yield prediction models.

A summary of important factors related to seasonal lodging risk assessment, lodging detection and yield loss is presented in Fig. 3. The figure also illustrates the potential contribution of RS in estimating lodging related parameters, as related to different factors.

\subsection{Field/lab-based methods for crop lodging assessment}

Based on the selected studies, we found that lodging has been studied most extensively in wheat (Crook and Ennos, 1993; Sterling et al., 2003) followed by barley (Stanca et al., 1979; White, 1991) and rice or cereals in general (Islam et al., 2007; Lang et al., 2012) (Fig. 4). Several methods and models of lodging assessment (stem and root lodging) have been developed for these crops (e.g., Baker et al., 1998; Berry et al., 2006). For instance, Caldicott and Nuttall (1979) adapted the prior work of Caldicott (1966) and Caldicott and Nuttall (1968), to develop a field-based visual/in situ assessment method for determining the lodging index/score in cereals. The index, on a scale of 1 


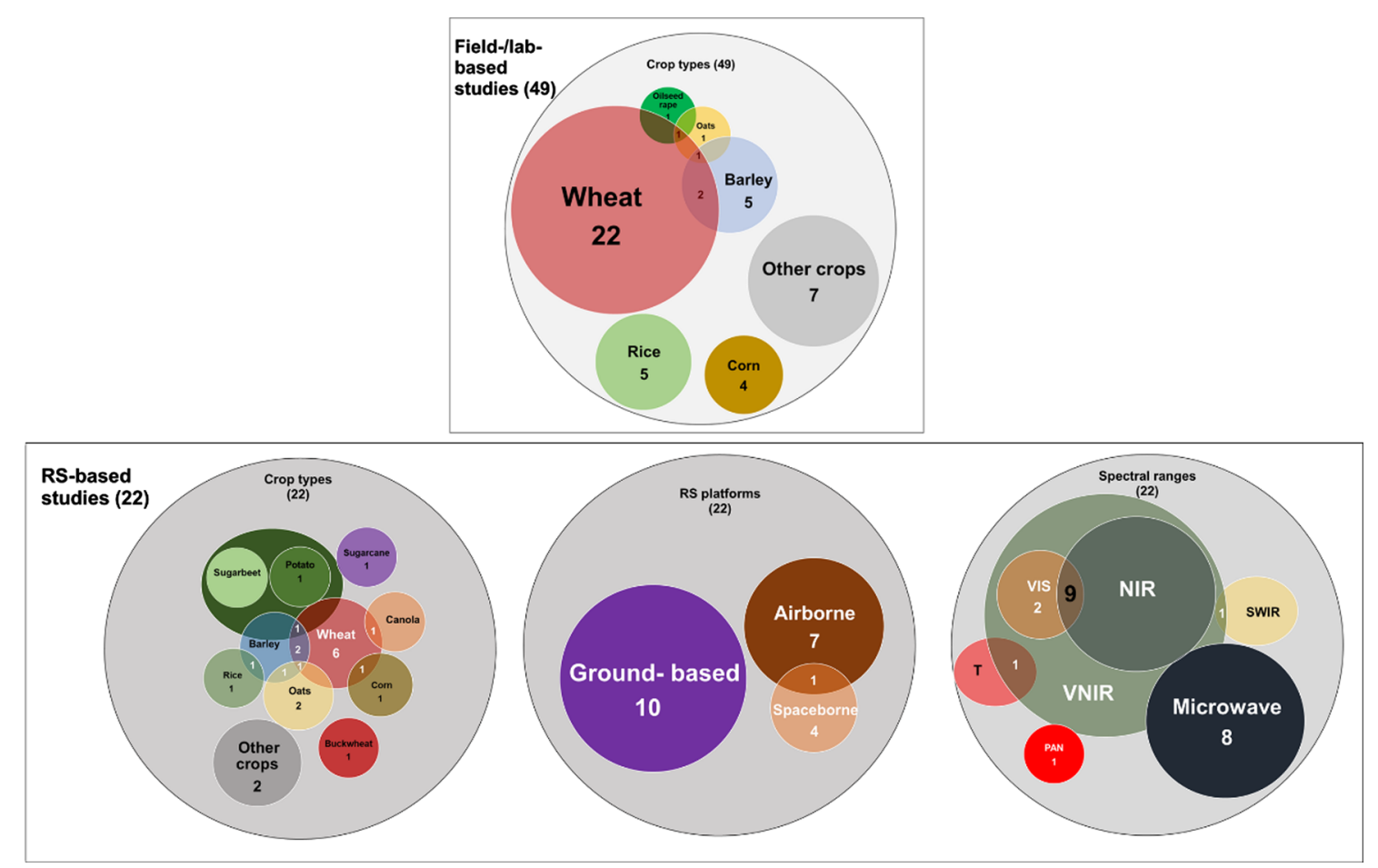

Fig. 4. The figure represents the number of reviewed articles based on the study type: field/lab-based studies and RS-based studies. The field/lab-based studies are further categorized based on the crop type while RS-based studies are divided into three categories: crop type, sensor spectral range (Visible to near-infrared or VNIR, shortwave infrared or SWIR, microwave, panchromatic band or PAN and thermal) and deployed RS platform (ground-based, airborne, and spaceborne).

(completely lodged) to 10 (no lodging), accounts for both spatial extent (area) and stage (angle) of lodging. Retrieval of the lodging index/score is an interesting application from RS perspective since current approaches are based on visual assessment/rating. The visual rating can be error-prone, subjective, unreliable, and sometimes unfeasible (for example, when assessing taller crops such as maize, it is difficult to make the assessment within the crop canopy) since it depends on the skill, experience, and self-consistency of the observer (Bock et al., 2010).

In another study, Baker (1995) made the first attempt to develop a theoretical model for the windthrow (i.e. uprooting or breakage by wind) of cereals and forest trees. The model was extended by Baker et al. (1998) to develop a quantitative lodging risk model for wheat. Sterling et al. (2003) and Berry et al. (2003) further refined and validated the model of Baker et al. (1998) to obtain more accurate model parameters. The fundamental assumption of these models is the depiction of a crop as a simple damped harmonic oscillator. These works have formed a basis of the methodology that is being used to guide farmers and agronomists in many countries (such as the UK) on ways to reduce lodging risk in wheat.

The applicability of these models has also been tested on other crops. For instance, Berry et al. (2006) extended the wheat-lodging model to barley. They suggest that a minor modification is needed to adapt the wheat root-lodging model to barley while the stem-lodging model needs to be changed substantially, owing to the less erect nature of barley ears, greater stem height, and increased flexibility. Similarly, Sposaro et al. (2010) developed a mathematical lodging model for sunflower based on existing models for wheat and barley. A more generalized model was developed by Baker et al. (2014) to calculate lodging risk in crops. The authors tested the model on barley, oats, and oilseed rape and found varying levels of uncertainties in the lodging risk for each crop. Mi et al. (2011) and more recently, Brune et al. (2017) also developed models to predict lodging risk in maize. Fig. 4 gives an overview of the field/lab-based studies categorized based on the crop type.
While these sophisticated models are promising and provide an understanding of the lodging process, they are data intensive, complex, point-based and computationally expensive. They also require prior knowledge and understanding of the input data for proper calibration and fine-tuning. Moreover, the model formulations are primarily based on empirical data and artificially induced or controlled lodging conditions. These models, therefore, need to be optimized before they can be extended on a larger scale. More straightforward methods are needed that can rapidly assess the biophysical parameters of crops and provide accurate measurements.

\section{Review of remote sensing-based studies for crop lodging assessment}

The traditional techniques of crop lodging assessment are visual rating/in situ assessment and sophisticated field/lab-based models. Visual rating is a direct way to evaluate the extent and degree of lodging damage in crops, but it has drawbacks as discussed previously. The field/lab-based models, on the other hand, are data intensive and largely based on empirical data. RS can complement the traditional methods and has the potential to extend our knowledge of crop lodging in space and time (Branson, 2011). The past decade has seen an increase in the use of RS for crop lodging assessment, although the research in this domain is still at an early stage. Broadly, the studies can be grouped into three categories based on the monitoring platform deployed: ground-based, airborne, and spaceborne. Table 1 lists the studies that demonstrate the use of different platforms of RS for crop lodging assessment in terms of the aim, crops studied, extent, scale, and significant findings.

\subsection{Remote sensing platforms for crop lodging assessment}

\subsubsection{Ground-based platforms}

Agricultural applications of RS have particular spatial, radiometric, and temporal resolution requirements (Inoue, 2003). For example, 


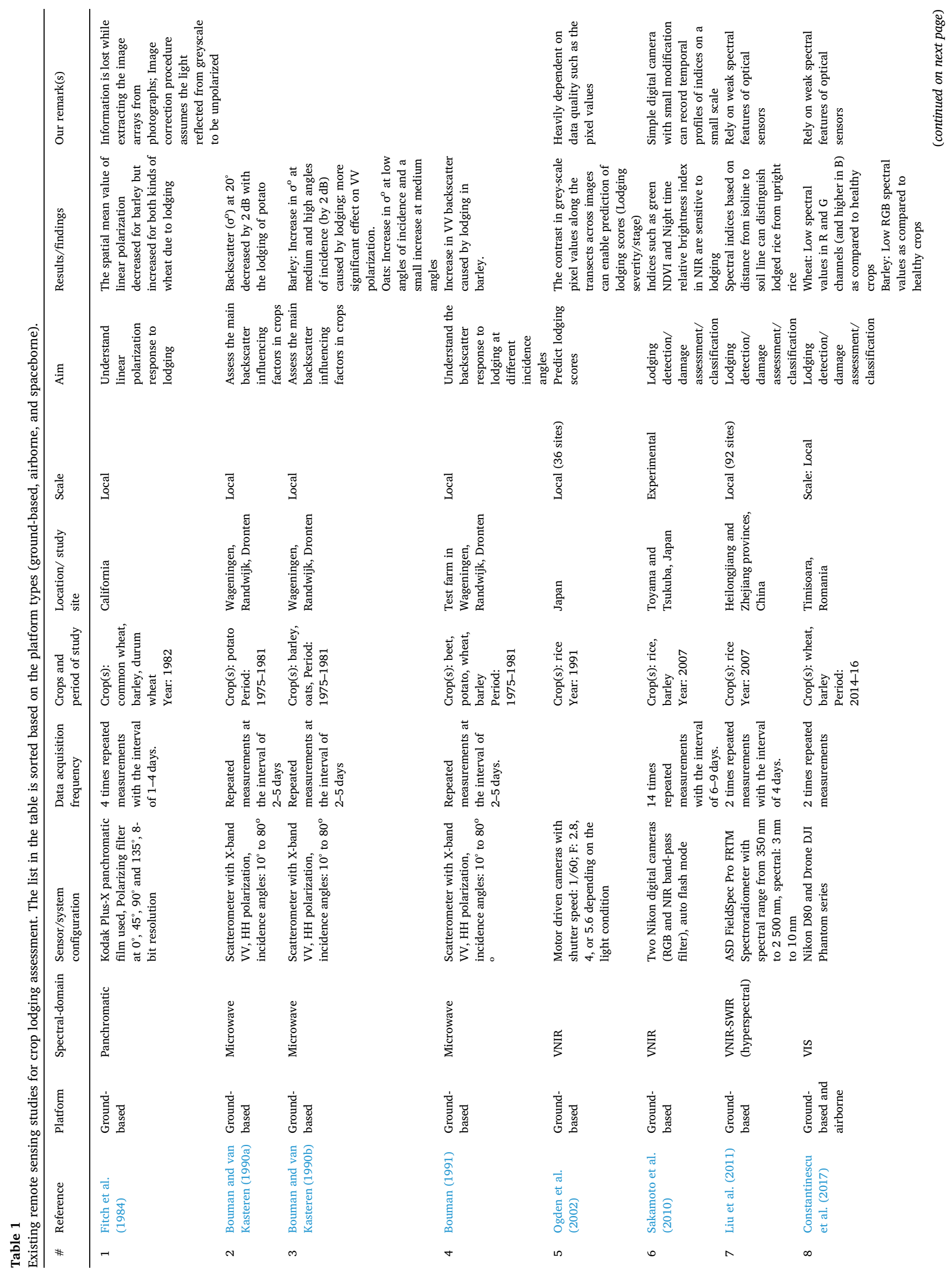




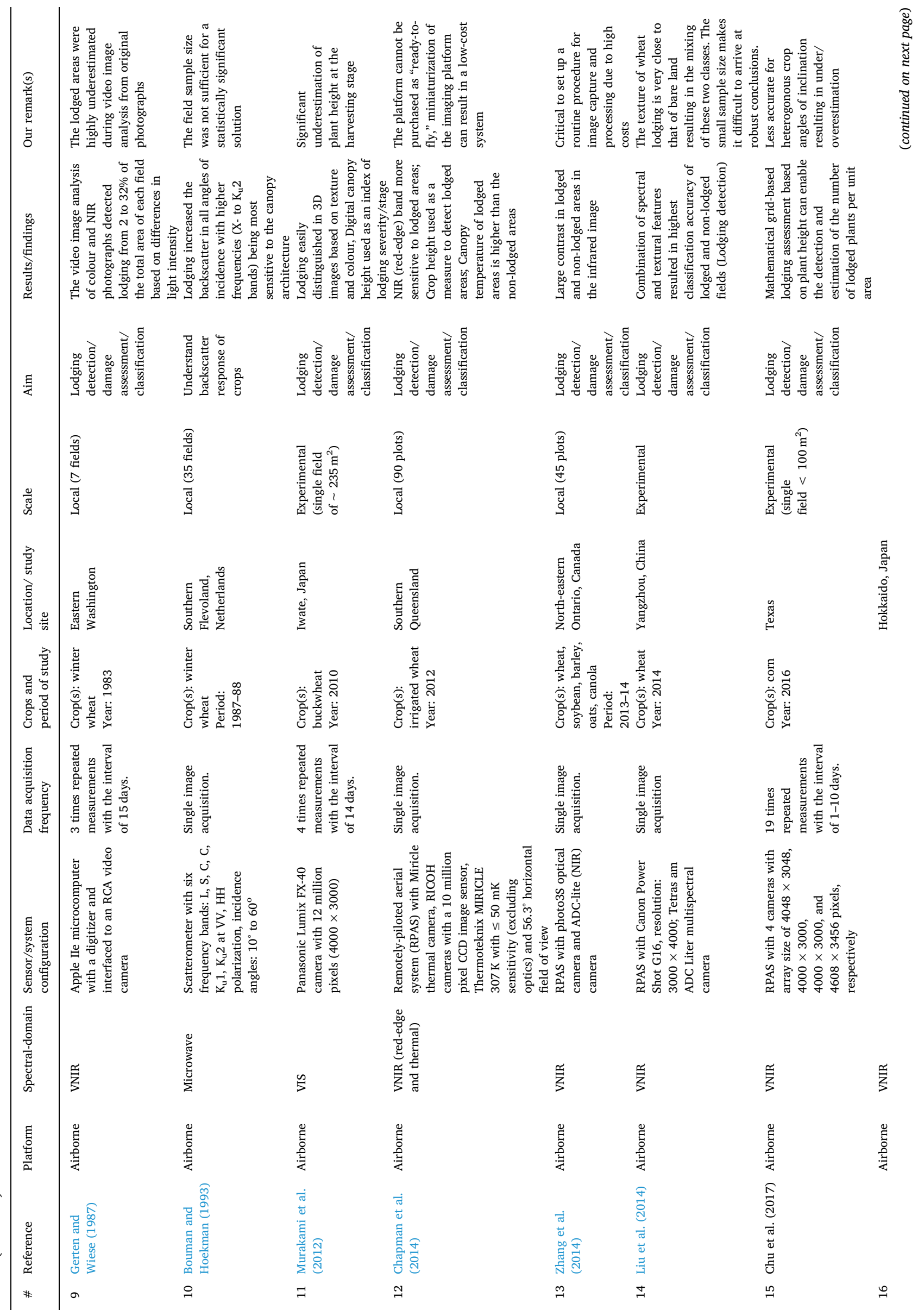




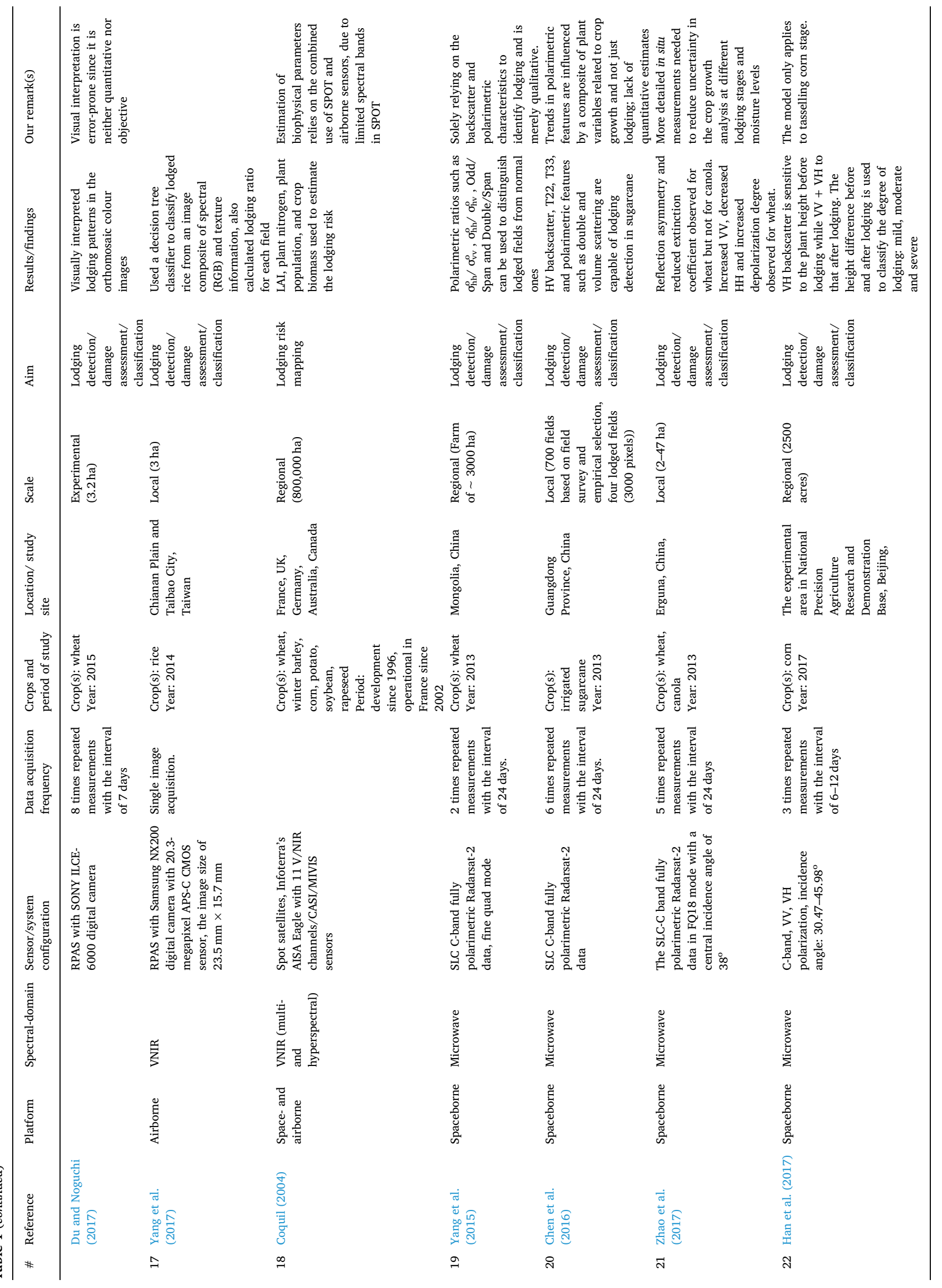


timely availability of diagnostic information on a crop's biophysical and ecophysiological status (such as LAI/GAI) is critical in the context of precision farming (Doraiswamy et al., 2004), while high spatial resolution is mandatory when observing fragmented crop fields or for assessing within-field variability (Cushnie, 1987). The motivation behind using ground-based or proximal sensing systems is mainly threefold: (i) ground conditions can be manipulated or conditioned to examine the effects of specific crop parameters; (ii) the mixed-pixel effect is reduced, and; (iii) high spatial resolution information is not constrained by weather conditions or platform revisit frequency, thus enabling timely implementation of required remedial action (Moran et al., 1997). Our review of the literature shows that most of the studies (10) have applied proximal sensing to analyze signal information from lodged crop canopies (Fig. 4). Of these, only a few deal with lodging as the central focus (e.g., Ogden et al., 2002), while the majority provide some valuable interpretations about the behaviour of the RS signal as induced by crop lodging (e.g., Fitch et al., 1984; Bouman and van Kasteren, 1990a; Sakamoto et al., 2010; see Table 1).

In lodged crop conditions, the signal that is reflected or backscattered at different wavelengths is affected by the changes in plant geometry and structure (LAI/GAI, distribution of leaf and stem inclination angles) (Hosoi and Omasa, 2012); crop morphology (crop height and biomass) (Murakami et al., 2012); and crop biochemical properties (such as chlorophyll content) (Clevers,1986; Setter et al., 1997; Baret et al., 2007). Multispectral and hyperspectral data have been exploited for lodging assessment in most of the investigations. Earlier work by Fitch et al. (1984) examined the linear polarization of light reflected from wheat and barley to determine its potential in detecting the differences in crop morphology. The spatial mean value of polarization showed a decreasing trend for barley, but an increase for wheat due to lodging.

In another study, Ogden et al. (2002) employed motor-driven cameras in paddy fields to investigate the use of textural information from digital images to measure the extent of lodging. They developed a quantitative method to predict the crop lodging scores on a scale of 0 (no lodging) to 5 (completely lodged). However, studies suggest that textural information alone fails to give effective classification results (Berberoglu et al., 2000) as different image characteristics, due to differences in vigour, soil type or phenology, may produce contradicting results (Sims and Gamon, 2002; Campbell and Wynne, 2011). Therefore, more studies need to be performed to validate the applicability of texture-based approaches for lodging assessment.

The use of optical hyperspectral measurements for detecting lodged and non-lodged rice has also been demonstrated by Liu et al. (2011). They observed that although the shape of the spectral signature of a lodged crop (from 400 to $2350 \mathrm{~nm}$ ) is similar to that of non-lodged crops, there is a significant increase in the spectral amplitude. Broadly, it can be concluded that studies employing proximal optical sensors mostly rely on the spectral reflectance-based measures to assess lodging state, but this approach has some contradictions. For example, Yang et al. (2015) state that the success of using spectral methods is limited to ideal situations only since the change in spectral features due to lodging is relatively weak. It is often drowned out in the complex mixed spectrum of features that optical data is sensitive to (like moisture stress, pesticide stress or pigment content).

The feasibility of studying geometric or structural characteristics of the canopy with radar data has long been recognized and is well documented (Brown et al., 2003; McNairn and Brisco, 2004). Since crop structural changes are evident in the event of lodging, observations made from SAR data can be useful in crop lodging assessment since lodged crops exhibit asymmetric polarimetric behaviour, in contrast to the symmetric behaviour portrayed by standing vegetation in the azimuth direction (Freeman et al., 1994). Ground-based SAR systems (such as scatterometers) can be instrumental in investigating the response of radar data to crop lodging due to the availability of a wide range of sensor configurations (such as multi-polarization, multi- frequency, etc.). For instance, Bouman and van Kasteren (1990a, 1990b) quantitatively estimated lodging-induced changes in radar backscattering with multi-parametric scatterometer data. The main findings of these studies are presented in Table 1. In another study, Bouman (1991) suggested that a sudden increase in radar backscatter from wheat could indicate lodging. However, such interpretations based on backscatter trends can be ambiguous since multiple factors determine radar backscattering (such as crop volume, water content, biomass, etc.). These studies also state that for a given crop type, the angle of incidence and state of polarization can contribute to high variability in the backscatter signal obtained from lodged crops. Our review suggests that there has been no detailed investigation of the suitability of different radar configurations and the use of polarimetric data to detect lodging.

With the increasing pressure and growing demand for efficient crop monitoring methods to improve management, there is a need to transfer the research from these scientific studies to agricultural practices. Proximal sensing is particularly suited for such applications, as it allows an "on-the-go" monitoring of the crop with high temporal resolution. However, there are some limitations to its commercial use in agriculture at this moment. For instance, the spatial coverage of proximal monitoring equipment is poor, even if mounted on fixed poles or moving vehicles (Maes and Steppe, 2012). In such scenarios, multiple sensors are required to view entire fields, which can be prohibitively expensive. With advances in ground-based sensors, it is now possible to mount some sensors directly on the operating tractor (e.g., GreenSeeker active canopy sensor; Trimble, Sunnyvale, CA, USA) and map the variability within a field during mechanisation activities.

\subsubsection{Airborne platforms}

Recent advancements in the development of RPAS, commonly known as drones, together with robotics, electronics and computer vision, have led to new opportunities in airborne RS (Nebiker et al., 2008; Colomina and de la Tecnologia, 2008). The fine spatial resolution and real-time monitoring ability of airborne RS suggest that it is well suited for applications that characterize changes in crop attributes over time. For example, airborne video imaging systems, LiDAR/RADAR data and RPASs have been applied to agricultural disaster (and post-disaster) assessment applications to meet the need for timely observational data (Everitt et al., 1991; Hunt et al., 2005; Weishampel et al., 2007; Rango et al., 2009; Huang et al., 2010, Ezequiel et al., 2014). Except for a few early applications, it is only in the last decade that the use of airborne platforms for lodging assessment has gained momentum. About $85 \%$ of these studies were published after 2010, emphasizing the growing interest of the RS scientific community in the subject (Fig. 1).

The earliest efforts can be traced back to the work of Gerten and Wiese (1987), and Bouman and Hoekman (1993). Gerten and Wiese (1987) employed an aerial video camera to identify lodging in winter wheat. They reported high under-estimation of the lodged areas due to problems in density slicing and lack of a microcomputer with enhanced graphics capabilities. Bouman and Hoekman (1993), on the other hand, analyzed the angular backscattering behaviour of lodged wheat at different frequencies using airborne scatterometer data.

With the development of miniature imaging instruments (such as scanning detectors and cameras) and an expanding pool of commercial vendors facilitating data acquisition and analysis, there has been a shift from aircrafts towards relatively low-cost systems such as RPASs. In comparison to proximal sensors, RPAS platforms can carry out surveys at a faster rate without disturbing the canopy cover (Burkart et al., 2015) and are more flexible than airborne and satellite-based systems, in terms of flight planning. They are increasingly being deployed as RS platforms for retrieving biophysical/biochemical parameters (Thenkabail et al., 2000; Li et al., 2010; Erdle et al., 2011), detecting environmental stress (Sullivan et al., 2007; Mahlein et al., 2013) and, more recently, for extracting lodged areas and estimating lodging severity (Liu et al., 2014; Yang et al., 2017). 
The importance of using airborne multispectral data has been reported by some studies. For instance, Constantinescu et al. (2017) studied the normalized reflectance RGB spectra of wheat and barley cultivars and identified distinct spectral features that differed notably across different bands. In lodged wheat, the normalized reflectance in red and green bands was lower than that in the blue band while in lodged barley; the reflectance in all the three bands was lower than the reflectance in non-lodged barley. They also employed Euclidean distance-based (between RGB bands) cluster analysis, which yielded distinct clusters of lodged and non-lodged crops. Furthermore, Zhang et al. (2014) performed a qualitative analysis of lodging (in the VIS-NIR region) in wheat and found that the lodged areas appear as a bright red tone in the IR image. Similar results were reported by Chapman et al. (2014) who additionally reported the significance of thermal images in detecting lodged areas. They found that the lodged areas appear hotter (higher surface temperature) in both day and night thermal images.

Textural features such as Grey-Level Co-Occurrence Matrix (GLCM) measures (Liu et al., 2014) have also been adopted in airborne RS for improving the classification accuracy of crop lodging. Texture usually provides supplementary information about the object properties, which can help in the assessment of heterogeneous crop fields (Pacifici et al., 2009), although they are highly dependent on image quality, resolution and have high computational cost. Factors such as growth stage, canopy structure, planting patterns and plant population density mainly define the textural pattern of the crops at a parcel-scale. Combining spectral and textural features often increases the accuracy of lodging classifications (Yang et al., 2017). According to Liu et al. (2014), incorporating texture information improved the lodging classification accuracy by up to $8-9 \%$. However, in hierarchical classification scenarios, selective application of textural information for specific classes becomes crucial since not all classes are separable based on a single textural measure (Yang et al., 2017). Also depending on the crop and its growth stage, the textural information can lead to contradictory results (Stroppiana et al., 2018). With a limited number of studies, it is difficult to conclude the significance of textural features for airborne lodging classification.

As discussed in Section 2.2, changes in crop morphological status affect the RS signal. While most of the studies rely on spectral changes and spatial variations to detect lodging, only a few studies have used plant traits (such as plant height) to detect lodging. For instance, Murakami et al. (2012) used digital canopy model-derived crop height as an index of lodging stage in buckwheat, with smaller values implying severe lodging. Broadly, there are two approaches for lodging detection using height information derived from RPAS or aerial stereo images: (1) height thresholding and (2) grid-based thresholding. Chapman et al. (2014) calculated the average height of lodged and non-lodged crops from a DEM and used a height threshold $(50 \mathrm{~cm}$, based on the variance in pixel heights) to identify lodged areas. The successful delineation of $10-70 \%$ of the lodged area using this approach seems to confirm the validity of using height information for lodging detection.

In a more recent study, Chu et al. (2017) investigated the potential of the grid-based thresholding approach to detect lodging. This method divides the image into grids and applies thresholds to each grid to detect the occurrence of lodging and can also be used to estimate the number of lodged plants. While this approach was applied successfully to detect lodging, the number of lodged plants were highly under/ overestimated. The authors suggest that such uncertainties can be due to the existence of mixed grids (where leaves from a non-lodged grid extend into a lodged grid) and estimation errors introduced by seed count (which ultimately affects the stand count and the number of lodged plants). In summary, substantial research efforts are still required to develop transferrable crop lodging detection algorithms to facilitate proper remedial actions.

As the initial trials have demonstrated promising results towards crop lodging assessment, the introduction of such portable RPASs opens up several research directions, such as assessing lodging stage, mapping its risk, measuring lodging spatial extent, and the time of its occurrence.
In comparison to the point measurements provided by proximal sensors, airborne sensors possess the capability to offer additional information associated with the patterns of lodging, thus allowing exploration of lodging events on a larger scale. Despite some interesting results, the quality of data from RPASs relies heavily on sky conditions and is affected by intervening atmospheric disturbances, cloud or snow cover, and solar radiation. Moreover, even though these systems deliver high spatial resolution data, radiometric responses can be different between the acquired frames and artefacts in vegetation condition can be generated. This could be due to the inability of the automatic systems to find homologous points between frames when creating orthomosaics. Finally, commercial and research RPAS can potentially be cost-prohibitive for regional or large-scale applications.

\subsubsection{Spaceborne platforms}

Spaceborne/Satellite-based platforms can monitor the textural and spectral characteristics of vegetation at varying spatial and temporal scales. They provide local to global coverage while offering data at different intervals: monthly (ERS, ASAR, RADARSAT-2), biweekly (Landsat), near weekly (Sentinel-1 and Sentinel-2) or approximately daily (NOAA-AVHRR, SPOT-VEGETATION, MODIS, PROVA-V and Sentinel-3). The resolutions (spatial, temporal, spectral, and radiometric) of satellite RS sensors are continuously improving through technical improvements in sensor technology, while access to imagery is improving through increased public and private investments in satellite platforms.

The availability of optimal spatial, spectral, radiometric, and temporal resolution actively governs the accuracy with which within-field spatial variabilities of lodging can be mapped. While moderate resolution sensors (e.g. AVHRR or MODIS) provide global coverage at daily intervals, their coarse spatial ( $>1 \mathrm{~km}$ ), spectral (5/6 bands) and radiometric (10/12 bits) resolution cannot capture such variabilities. Satellites such as Landsat-7/8 with $30 \mathrm{~m}$ spatial resolution (and 8/11 spectral bands, 9/12-bit radiometric resolution), on the other hand, have lower revisit times ( $\sim 16$ days) which are impractical for lodgingrelated applications. The spatial resolutions have improved in some recent satellite sensors such as Sentinel-2 (10 or $20 \mathrm{~m})$, Sentinel-1 $(20 \times 22 \mathrm{~m})$ (from the European Space Agency), or commercial providers such as Worldview-4 (31 cm in the panchromatic and multispectral at $1.24 \mathrm{~m}$ ) and IKONOS-2 $(1 \mathrm{~m})$. However, free access to high-resolution temporal spaceborne images becomes crucial if operational satellitebased quantitative applications are to be developed.

In our review, we found only a few studies that used satellite-based RS to assess crop lodging (Fig. 4). To the best of our knowledge, the first study that demonstrated the capability of radar-based satellite data to address the problem of lodging was performed in 2015 on a farm scale extending over 3000 ha (Yang et al., 2015). Until then, the potential of SAR satellite data for crop lodging assessment was undetermined. Building upon the findings of earlier studies that have established the unique sensitivity of SAR to vegetation structural changes (Ulaby et al., 1986; Balenzano et al., 2011), some studies have explored RADARSAT-2 quad-polarimetric data to assess lodging in wheat and sugarcane (Yang et al., 2015; Chen et al., 2016; Zhao et al., 2017). The studies suggest that advanced polarimetric parameters such as scattering ratios, circular-pol correlation coefficients, etc. and time-series data can enhance the discrimination of lodged areas from non-lodged.

However, these studies address lodging qualitatively and do not provide quantitative estimates of lodging stage or extent. Such estimates are important in predicting the yield losses or assessing grain quality. For instance, Fischer and Stapper (1987) demonstrated that the yield losses incurred at a lodging angle of $80^{\circ}$ are almost 2-4 times than those at $45^{\circ}$ in wheat. Furthermore, the selected sites in these studies comprise of relatively homogeneous fields. It remains a challenge to address lodging in areas with complex and fragmented agricultural fields. While a majority of the studies have exploited the advanced capabilities of RADARSAT-2 satellite data (a single platform, 


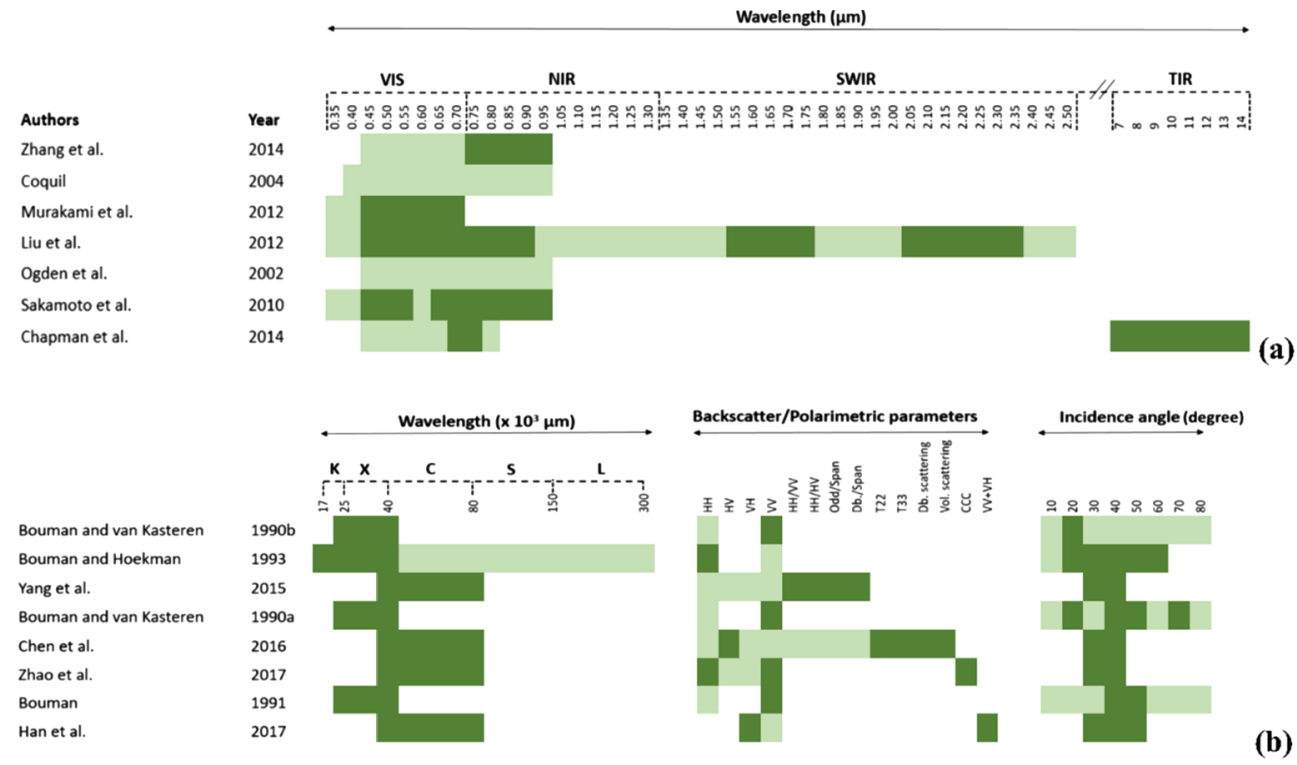

Selected features $\quad \mathrm{H}$ : Horizontal V: Vertical Odd: Odd/single bounce scattering Db.: Double bounce scattering Vol.: Volume scattering Total range considered T22, T33: Components of Pauli decomposition Span: Total scattering power in HH, VH, HV, VV CCC: Circular-pol correlation coefficient

Fig. 5. Summary of important features in (a) optical and (b) microwave region relevant to crop lodging detection and risk assessment as identified from the RS-based crop lodging studies. The light green color indicates the entire wavelength range of the respective sensors, the total number of backscatter/polarimetric parameters and the range of incidence angles that were tested in the selected studies. The dark green color indicates the specific wavelength region, backscatter/polarimetric parameters and incidence angles that are sensitive to lodging (according to the results of these selected studies). (For interpretation of the references to color in this figure legend, the reader is referred to the web version of this article.)

commercial data source with limited revisit frequency), we found only one study that used freely accessible satellite data with a high temporal resolution to map lodging severity. Recently, Han et al. (2017) built a quantitative lodging classification model for maize using height information derived from Sentinel-1 data. It is a first step towards the use of satellite data for quantitative modelling of lodging stage.

Above all, the main problem is the inability to predict where and when lodging is likely to occur. An early season assessment of lodging risk can support more accurate and cost-effective targetting of lodging control measures. While more studies have been undertaken to detect lodging using spaceborne data, there is only one study which has explored the use of satellite images for seasonal lodging risk mapping at a regional scale. Coquil (2004) describes the FARMSTAR commercial service that was launched successfully in France in 2002. It is a decision support tool for sustainable crop management, seasonal lodging risk mapping being one of its application. The service is based on the integration of RS images, agronomic expertise, and meteorological data and is still operational. It exploits SPOT images to measure crop biophysical parameters (LAI/GAI, chlorophyll content and biomass) which are then analyzed and transformed into seasonal lodging risk maps for the second plant growth regulator (PGR) spray. The product has been tested on different crop types: wheat, corn, soybean, barley, potatoes, etc. and it is being transferred to other countries: such as Germany, UK,

Spain, Canada and Australia. However, the spectral bands of SPOT pose a great challenge for the estimation of chlorophyll content and LAI/GAI (since more bands are required to decouple the absorption features of these biophysical parameters from other physical effects). As a result, highly accurate $a$ priori information needs to be fed into the model inversion process, making the model data intensive. Therefore, FARMSTAR relies on the combined use of SPOT and airborne sensors (CASI, AISA Eagle, and MIVIS) to ensure better spatial and spectral coverage for an accurate estimation of crop parameters. The applicability of spaceborne RS for lodging can thus be constrained by limited spectral bands, in addition to lower revisit times, coarser spatial resolutions and high acquisition/processing costs (in most cases).
In view of these studies, the majority of the RS contributions for crop lodging assessment can be categorized in terms of crop type, RS platform, and sensor spectral range, as illustrated in Fig. 4.

\subsection{Important wavelength regions and remote sensing parameters}

The findings of many studies underline the importance of different wavelength regions in detecting lodging and assessing its risk (e.g., Zhang et al., 2014; Yang et al., 2015). Fig. 5 illustrates important wavelength regions and other RS parameters retrieved from the major RSbased crop lodging studies that used optical and microwave data. Fig. 5a reveals that the important wavelength intervals (marked as dark green) mainly correspond to the absorption bands of plant pigments and water, thus corroborating the hypothesis that they are the main components of lodging detection in VIS-SWIR region. Some studies have highlighted the significance of the near-infrared (NIR) and rededge regions for lodging assessment (Sakamoto et al., 2010; Chapman et al., 2014). Zhang et al. (2014) discuss the relevance of NIR reflectance in detecting lodging in wheat since a strong increase in the reflectance from wheat leaves and stems is recorded in NIR region (and relatively less from the underlying soil as lodged crops entirely cover it).

Crop lodging information from SAR mainly relates to crop structural parameters such as crop angle and height. The estimation of these features depends on the SAR band, the incidence angle, as well as polarization modes, in addition to terrain and weather conditions. The SAR band (or its wavelength) describes the penetration depth of a signal through the crop canopy, with shorter wavelengths (e.g. K-, X-, C-band) interacting mainly with the top canopy and longer-wavelengths (e.g., L-, P-band) penetrating deeper through the canopy and yielding backscatter from both stems and soil (Ulaby et al., 1984). Concerning the selection of optimal SAR band for crop lodging assessment, studies show that shorter wavelengths, namely $\mathrm{X}$ - to $\mathrm{K}_{\mathrm{u}} 2$-bands are more suitable for assessing lodging (Bouman and van Kasteren, 1990a; Bouman and Hoekman, 1993). Similar conclusions regarding 
the potential of C-band for studying lodging in "narrow-leaf" crops such as wheat have been made by Yang et al. (2015) and Han et al. (2017). These results are summarized in Fig. 5b.

Apart from emphasizing the importance of specific wavelengths in assessing lodging, some studies also outline the additional information obtained from different polarizations and incidence angles (Bouman, 1991; Zhao et al., 2017). The potential of different polarizations and incidence angles to detect lodging was first reported in the earlier works of Bouman and van Kasteren (1990a, 1990b) and Bouman and Hoekman (1993). Yang et al. (2015) suggest that the backscatter from a single channel (HH or HV or VV) cannot distinguish the lodged wheat parcels from non-lodged ones while a polarimetric index can enhance the detection capability (Fig. 5b). Chen et al. (2016), on the other hand, found that HV backscatter intensity alone could distinguish lodged and non-lodged sugarcane fields, in addition to other polarimetric features. However, it is important to mention that these features (backscatter and polarimetric) are also related to crop growth, senescence, density and plant stress (Patel et al., 2006). Therefore, while such features can be affected by the relative contributions of various scattering mechanisms, parameters that are uniquely diagnostic of crop lodging, still need to be found. More recently, Zhang et al. (2017) studied the sensitivity of correlation coefficients (co-, cross-, and circular-pol) to lodging in wheat and canola. They found that co-pol and circular-pol correlation coefficients are uniquely sensitive to lodging in wheat but not in canola. As reflection asymmetry described by the circular-polarization coefficient is an identifiable feature of lodged wheat, this observation seems to be very promising for lodging detection.

\section{Challenges in remote sensing of crop lodging}

The contribution of RS data to operational crop monitoring systems is increasing (Atzberger, 2013). However, several challenges have prevented the integration of RS data into routine crop lodging assessment. Primarily it is the availability of high spatial resolution data at low costs. The heterogeneous distribution of lodging directly affects our ability to detect it using RS. In general, to map lodging accurately, the spatial resolution of the sensor must be smaller than the size of the field and the lodged area. However, high spatial resolution alone is not sufficient. High temporal resolution information is also important to improve lodgign detection, and to know the phenological stage at the lodging occurrence, which rules its severity. With coarse resolution data, more frequent observations are available but with pronounced mixed-pixel effects. For instance, consider a single MODIS 250-meter pixel, which corresponds to an area of 6.25 ha, while a Sentinel-2 10/ 20 -meter pixel covers $0.01 / 0.04 \mathrm{ha}$. In this case, the lodged area would fall in only a fraction of the coarse spatial resolution pixel of MODIS, while in the latter case; there is a possibility to extract a unique signature from lodging.

Selection of optimal spectral bands (optical) or polarizations (radar) that are uniquely sensitive to lodging is also challenging. For example, while several indices have been tested for retrieving crop biophysical parameters (e.g. crop biomass), the cause of their spatio-temporal variations, whether due to crop growth or lodging, is much less straightforward and hence more difficult to determine. The accuracy assessment of lodging severity and lodging risk maps poses another issue, given the absence of a standard reference scale to represent lodging (e.g., mild, moderate and severe). In terms of "severity," each lodging event is unique, with differing characteristics regarding onset, duration, and intensity. Many qualitative/quantitative assessment techniques such as comparison with in situ observations (e.g., crop height or precipitation); crop statistics (e.g., yield or grain quality) and expert ground-level visual ratings can be used. However, there is no consensus about the most appropriate method for producing and validating lodging maps. Unfortunately, there is a dearth of statistics/data related to lodging on the local, regional, and global scale, unlike crop yield.
The collection of ground truth data (such as crop height, crop angle, lodged area) to assess lodging damage can itself be a daunting task, due to unfavourable weather conditions and irregular plant structures. A considerable investment in time and resources is required to plan and perform such campaigns. Furthermore, acquisition of RS data coincident to specific dates, especially from spaceborne platforms, may not always be feasible. This can consequently hinder the application of RS data close to the onset of the lodging event, making it difficult to capitalize on the current lodging information being reported (e.g., lodged area) and in situ data (e.g., crop height) being collected. Seasonal lodging risk mapping, on the other hand, requires specific growth stages to be covered so that in-season remedial actions can be undertaken. For instance, the crop nitrogen status and plant population density at the start of stem elongation (GS 30-31, according to the Zadoks growth scale) in wheat can be indicative of the fertility of a field and therefore its propensity to lodge. An assessment of these attributes with RS (directly) can be crucial to map the potential risk of lodging and target proper management strategies.

\section{Research gaps and future scope}

Active engagement of the RS community with crop physiologists is important for successful integration of EO products into lodging assessment. The Earth Science Decadal Survey (Board and NRC, 2007) emphasizes the need to form a stronger linkage between RS scientists and end-users to define data requirements in a better way and disseminate knowledge to the users to be able to apply the EO data to specific applications. The end-users, for instance, loss adjusters, could provide real case scenarios, covering the spatiotemporal complexity of lodging phenomena. Moreover, end users should be engaged, in future, in the provision of crowdsourced lodging information directly from the field, thus promoting Citizen Science (CS) initiatives, and exploiting smart technologies, such as those used by Dickinson et al. (2012) and Fritz et al. (2009) in ecology and land cover mapping. This kind of interaction can be fruitful, not only for the collection of a large amount of data but also for raising user awareness regarding the use of RS information for crop management.

RS can be a convenient and efficient method to monitor crop lodging, but its use within operational lodging detection or seasonal risk assessment faces some challenges. In this review, we made the first attempt to consolidate research progress in the field of RS while categorizing different studies into major groups. We found only 22 publications that explored the potential of RS to study lodging. The early work on assessment of crop lodging with RS date back to the 1980s, however, significant progress has been made post-2000. Nevertheless, there are still many prospective research areas that merit further investigation.

\subsection{Lodging detection}

The current literature on RS-based lodging assessment suggests that there is a large group of studies ( $68 \%$ of the reviewed studies) focusing on lodging detection-driven questions (see Table 1). Although timely detection of crop lodging (lodged/non-lodged) can be beneficial to plan harvest operations, such qualitative analyses can be of limited use since the yield losses or deterioration in grain quality cannot be directly quantified. There is scope to develop quantitative approaches for applications such as estimation of lodging stage by measuring lodging angle/crop angle of inclination or lodged crop height. The crop angle of inclination can also be used to predict crop lodging scores, which are otherwise evaluated by visual assessment of lodged fields. The potential of radar polarimetry and suitability of different radar configurations in characterizing crop structural properties (Hosoi et al., 2009; Gherboudj et al., 2011), should also be further explored.

A potentially interesting avenue for future research is to explore how the spatial lodging extent (area) and lodging rate (i.e., number of 
lodged plants per unit area) can be estimated remotely. An accurate estimation of these parameters, close to the lodging event, can enable a farmer or a loss adjuster to evaluate crop loss, quantitatively support damage assessment, and aid in agricultural disaster relief compensation. For instance, according to the regulations of the Agricultural Natural Disaster Relief system in Taiwan, if lodging in a sampled area exceeds $20 \%$, it is considered as a disaster area, and a sampling accuracy of $>90 \%$ is required to be able to allocate funds to restore the damaged crop (Yang et al., 2017). Furthermore, the images captured before harvesting can enable an assessment of the lodged patches in a field and can practically result in navigation maps to guide the drivers or autonomous harvesting vehicles to adjust their speeds based on the lodging situation.

We also found that in most of the studies, the re-occurring method to detect crop lodging is the use of spectral and textural indices from optical imagery. The drawback of using spectral indices is that the change/variability in these features may actually be caused by a composite of factors other than lodging, such as soil conditions, water or nutritional stresses, leaf pigment concentrations, canopy structure, pests, diseases, etc. (Patel et al., 2006; Schaepman et al., 2009). Therefore, it is difficult to automatically detect and recognise the evidence of lodging amongst these factors. More diagnostic measures that are strongly sensitive to lodging should be investigated, though some attempts have been made by Zhao et al. (2017) and Chapman et al. (2014) in this direction. Another finding of our review is that there are very few examples of crop lodging detection over large areas. Bridging the gap between current approaches and crop lodging assessment over large spatial extents is still one of the major challenges in this field. From 22 reviewed cases, only five studies (as shown in Fig. 4) explored lodging using satellite data (e.g., Yang et al., 2015; Chen et al., 2016). The rapid and ongoing developments of new RS sensors in the recent years (e.g., Sentinel-1, Sentinel-2, Worldview-4, etc.) and the forthcoming missions (e.g. RADARSAT constellation mission that will provide compact-pol data in addition to quad-pol data) can provide highresolution spatiotemporal data that could meet the data requirements of crop lodging assessment. Furthermore, the utility of thermal datasets for lodging assessment seems to be under-examined, as it was investigated in only one study (Chapman et al., 2014). The data from spaceborne thermal sensors may not offer fine spatial resolution but can be integrated into ensemble sensor fusion/multi-sensor cross-calibration frameworks to derive lodging information over large geographical extents.

\subsection{Lodging risk}

We found seasonal RS-based lodging risk mapping to be another interesting (yet under-explored) research field. Sophisticated mathematical models based on the underlying physics of plant structure have been formulated to predict lodging risk quantitatively (Baker et al., 1998; Berry et al., 2003). However, their complexity and reliance on intensive field measurements of input parameters make it difficult to apply them widely. The mapping capabilities of RS can be used to quantify the variation in crop biophysical parameters (such as crop nitrogen, plant population density, etc.) so that remedial treatments can be targeted more efficiently. To date, seasonal RS-based lodging risk mapping has been reported by only one study (Coquil, 2004), but the results are still not conclusive. Research along these lines would require building upon earlier efforts (Crook and Ennos, 1994; Baker et al., 1998; Berry et al., 2006; Sposaro et al., 2010; Martinez-Vazquez and Sterling, 2011) that modelled the risk of lodging in various crops (such as wheat, barley, and sunflower) using intensive ground measurements. In our view, future studies should develop stand-alone geo-information products/models for the provision of seasonal lodging risk maps to facilitate proper crop recommendations and management. It is envisioned that such seasonal lodging risk models could also contribute to climate change resilience of agricultural practices since lodging risk is directly associated with the increased frequency of extreme rainfall and wind events.

\section{Outlook on remote sensing sensors and platforms}

Timely and accurate monitoring of crop lodging at multiple scales can provide insights into its spatial and temporal dynamics. The need for large and fine-scale analysis for agricultural applications has boosted the ongoing efforts in developing high-end sensors and monitoring platforms. Recent developments in RS have resulted in new satellite missions, such as the Sentinel series, which provides free data while continuously mapping the Earth at short time intervals. Other missions such as RADARSAT-2 and COSMO-SkyMed (constellation of four satellites), RapidEye (five-satellite constellation), DigitalGlobe (constellation of Worldview and GeoEye high-resolution satellites), DMC (Disaster Monitoring Constellation) and Planet (with $175+$ satellites in orbit) also provide flexible monitoring options imaging the Earth's landmass at monthly to daily time intervals. This large series of multi-temporal datasets can serve as a sound basis for detecting and mapping crop lodging.

Until recently, the availability of spectral data from the red-edge region, which is highly sensitive to crop's biophysical parameters such as biomass (Mutanga and Skidmore, 2004; Chen et al., 2009), and indirectly to lodging, was limited to certain hyperspectral sensors. The scenario changed with the launch of RapidEye (in 2008), Worldview-2 (2009), Worldview-3 (2014), and more recently with Sentinel-2A (2015), Worldview-4 (2016) and Sentinel-2B (2017). There is little research on whether broadband red-edge, satellite data $(>10 \mathrm{~nm})$ can detect high biomass values or lodging-induced changes in crops. Although local-scale studies may benefit with very high spatial resolution data from commercial missions such as Worldview (2-4), availability of freely available satellite data (such as from Sentinel) can be a motivation to investigate such approaches on a larger scale. The VSSC (VEN $\mu$ S Superspectral Camera) on board the VEN $\mu$ S (Vegetation and Environment monitoring on a New MicroSatellite) spacecraft, launched in 2017, is another sensor providing red-edge data at high spatial resolution $(5.3 \mathrm{~m})$ and two-days' revisit time. Future hyperspectral missions such as PRISMA (scheduled in $2018,30 \mathrm{~m}$ spatial resolution), HISUI (2019, $20 \mathrm{~m}$ ), EnMAP (2020, $30 \mathrm{~m}$ ), HyspIRI (2022, $60 \mathrm{~m}$ ), $\operatorname{SHALOM}(2021,10 \mathrm{~m})$ will deliver super-spectral information at moderate $(60 \mathrm{~m})$ to high $(10 \mathrm{~m})$ spatial resolutions and have the potential for regional scale applications.

Lodging happens in adverse climatic conditions, and the all-weather data capability of SAR platforms have the potential for developing operational applications. Among the satellite sensors, studies have predominantly used RADARSAT-2 for assessing crop lodging. RADARSAT-2, with its ability to acquire data in quad-polarizations (HH, HV, $\mathrm{VH}, \mathrm{VV}$ ), reduces the need to acquire data over several dates. Moreover, data from recently launched SAR missions such as L-band ALOS-2 (2014) and C-band Sentinel-1A and B $(2014,2016)$ have not yet been explored for lodging assessment (except Han et al., 2017). Although the limited feature space of Sentinel-1 data (dual-pol data) may not characterize the heterogeneous patterns of lodging in the same way as RADARSAT-2, free data access and high temporal resolution make it particularly relevant for developing operational applications. Furthermore, the frequency $(5.4 \mathrm{GHz})$ of Sentinel-1, unlike ALOS-2 $(1.2 \mathrm{GHz})$, is more sensitive to the phenological changes and volume scattering from crops, such as wheat with moderate plant height, providing an excellent contrast in the dynamic range of backscatter response from a crop and the underlying soil cover. Also, the multi-sensor fusion of Sentinel-2 with either Sentinel-1 or RADARSAT-2 data should be investigated due to the complementary nature of microwave and optical signals.

We are confident that field level research on the application of airborne multi/hyperspectral as well as microwave data for crop lodging assessment will continue. The availability of airborne data is 
slowly reaching an operational level and can be obtained over large spatial extents, as exemplified in the national ecological observatory network (NEON, http://www.neoninc.org) (Keller et al., 2008). RPASs may become even more powerful, due to continued improvements in spatial and spectral resolution of the sensors on board RPASs and their ability to provide information to meet specific temporal requirements. RPAS data can be used either directly as a dataset to assess lodging on local scales or can serve as additional reference information for satellite or airborne datasets. The second solution is more viable when large areas have to be mapped. RPAS reference data can provide detailed information on lodging extent or crop properties such as stem diameter and shoot numbers, which could then serve as explanatory variables to interpret the success or failure of lodging detection or seasonal risk mapping algorithms using coarser RS data.

\section{Conclusions}

The accurate and timely assessment of lodging and its risk is a challenging prospect. In this paper, we make a first attempt to review the progress towards this goal and at classifying different studies in some major groups. Given the demand for rapid and quantitative evaluation of crop lodging (and its risk), with evidence from 22 studies, RS data has been explored for lodging assessment during the last three decades. RS measurements of crop lodging are needed for crop models; however, the methodology has not yet reached sufficient maturity in an operational context. Here we attempt to fill the current gap in RS reviews by placing a focus on crop lodging assessment. The main findings of the review are:

(i) A comprehensive review of 71 studies showed that lodging is one of the major yield-reducing factors in crops and is a global phenomenon. Viable solutions for its detection and seasonal risk mapping require knowledge of crop biophysical parameters (such as crop height, crop nitrogen, LAI/GAI, etc.) during the crop growth as potentially derived from RS data and processing chains that can contribute to the development of practical/operational applications.

(ii) The number of RS-based studies focusing on crop lodging assessment has increased in the last decade, but the research is still at an early stage. We found only 22 RS-based articles that studied lodging of which 15 were lodging-detection driven investigations, 6 focused on understanding the response of RS signal under lodged conditions, while only one study explored the capability of RS technique for seasonal lodging risk mapping (see Table 1).

(iii) Studies working on a large spatial scale with satellite-based data are still sparse (only five studies). To date, there is no rapid method available for the quantitative evaluation of crop lodging over large areas. With the ongoing developments in sensor technologies and reducing data acquisition costs, the satellite data (such as those from Sentinel missions) has great potential in the context of operational applications.

(iv) Robust methodologies and algorithms are needed to deal with lodging detection and seasonal risk mapping quantitatively. They should focus on investigating representative/diagnostic measures of crop lodging from RS.

(v) Most research regarding crop lodging has been conducted with optical RS data. Very few studies have examined other spectral regions such as SWIR bands, thermal infrared or microwaves, which might be due to the constraints on data access or lack of expertise. For instance, before the advent of Sentinel-1 data, SAR data was available only from commercial (RADARSAT, ALOS, COSMO) or scientific space agency platforms (e.g. ASAR from ENVISAT of ESA) with biweekly or monthly frequencies, making it difficult to study lodging phenomena. Future research efforts should investigate ensemble sensor fusion approaches to extract lodging information. (vi) The results from existing RS studies are mostly qualitative. For instance, the focus of most of the studies was to analyze the trend of the RS signal in lodged and non-lodged crop conditions. The goal of the future studies should be to develop robust, empirically tested quantitative models that can support in season lodging risk mapping and assess the lodging affected areas and severity of the events. The models can be enhanced by assimilation of crop biophysical parameters (such as fresh biomass, height, LAI/GAI, chlorophyll content) and phenological information (e.g. sowing date) derived from RS data. This may provide an alternative to complex models that need extensive parameterisation and huge amount of ground data.

(vii) The greatest number of remote sensing-based lodging studies has been carried out for wheat and barley, through the development of lodging detection models and the identification of different bands/ indices/wavelengths/incidence angles that are sensitive to lodging. This has underpinned most of the current understanding of the response of remote sensing variables to wheat and barley lodging. There are few remote sensing-based studies on other crops such as corn, oats, rice, canola, and sugarcane. Genetic, structural and physiological differences, as well as crop-specific management practices, may influence the incidence and intensity of lodging in different crops. For instance: in comparison to wheat, barley stems are more flexible, the ears are less erect, and barley has awns, which can affect the lodging model parameters significantly; the pods in canola provide a high degree of randomness to the canopy structure, which causes the scattering properties to be significantly different from other crops. These differences suggest that (a) genetic, environmental and management differences should be accounted for when considering the relevance of observed relationships between remote sensing information and lodging between one crop production situation and another and, (b) a need for further remote sensing studies of lodging across diverse crops, including studies of multiple crops with the same imagery.

\section{References}

Acreche, M.M., Slafer, G.A., 2011. Lodging yield penalties as affected by breeding in Mediterranean wheats. Field Crops Res. 122 (1), 40-48.

AHDB, 2005 Avoiding lodging in winter wheat - practical guidelines. https://cereals. ahdb.org.uk/media/187465/g25-avoiding-lodging-in-winter-wheat-practicalguidelines.pdf (accessed 10 July, 2017).

Asrar, G., Kanemasu, E.T., Yoshida, M., 1985. Estimates of leaf area index from spectral reflectance of wheat under different cultural practices and solar angle. Remote Sens. Environ. 17 (1), 1-11.

Atzberger, C., 2013. Advances in remote sensing of agriculture: Context description, existing operational monitoring systems and major information needs. Remote Sens. 5 (2), 949-981.

Bai, J., Li, J., Li, S., 2010. Monitoring the plant density of cotton with remotely sensed data. In: Computing Technologies in Agriculture. Springer, Berlin, Heidelberg, October, pp. 90-101.

Balenzano, A., Mattia, F., Satalino, G., Davidson, M.W., 2011. Dense temporal series of Cand L-band SAR data for soil moisture retrieval over agricultural crops. IEEE J. Sel. Top. Appl. Earth Obs. Remote Sens. 4 (2), 439-450.

Baker, C.J., 1995. The development of a theoretical model for the windthrow of plants. J. Theoret. Biol. 175 (3), 355-372.

Baker, C.J., Berry, P.M., Spink, J.H., Sylvester-Bradley, R., Griffin, J.M., Scott, R.K., Clare, R.W., 1998. A method for the assessment of the risk of wheat lodging. J. Theoret. Biol. 194 (4), 587-603.

Baker, C.J., Sterling, M., Berry, P., 2014. A generalised model of crop lodging. J. Theoret Biol. 363, 1-12.

Baret, F., Houles, V., Guérif, M., 2007. Quantification of plant stress using remote sensing observations and crop models: the case of nitrogen management. J. Exp. Bot. 58 (4), 869-880.

Baret, F., Weiss, M., Lacaze, R., Camacho, F., Makhmara, H., Pacholcyzk, P., Smets, B., 2013. GEOV1: LAI and FAPAR essential climate variables and FCOVER global time series capitalizing over existing products. Part1: Principles of development and production. Remote Sens. Environ 137, 299-309.

BASF, 2011. Managing lodging risk in winter wheat. Featuring the new Canopy Assessment Tool (CAT). https://www.agricentre.basf.co.uk/agroportal/uk/media/ marketing_pages/pgrplus/CanopyAssessmentToolPocketGuide.pdf (accessed 26 July 2018).

Baylis, A.D., Wright, I.T.J., 1990. The effects of lodging and a 
paclobutrazol—chlormequat chloride mixture on the yield and quality of oilseed rape. Ann. Appl. Biol. 116 (2), 287-295.

Berberoglu, S., Lloyd, C.D., Atkinson, P.M., Curran, P.J., 2000. The integration of spectral and textural information using neural networks for land cover mapping in the Mediterranean. Comput. Geosci. 26 (4), 385-396.

Berry, P.M., 2013. New Advances in PGRs. BCPC 50 year Anniversary Conference. Rothamsted, UK.

Berry, P.M., Griffin, J.M., Sylvester-Bradley, R., Scott, R.K., Spink, J.H., Baker, C.J., Clare, R.W., 2000. Controlling plant form through husbandry to minimise lodging in wheat. Field Crops Res. 67 (1), 59-81.

Berry, P.M., Sterling, M., Baker, C.J., Spink, J., Sparkes, D.L., 2003. A calibrated model of wheat lodging compared with field measurements. Agric. For. Meteorol. 119 (3-4), 167-180.

Berry, P.M., Spink, J., 2012. Predicting yield losses caused by lodging in wheat. Field Crops Res. 137, 19-26.

Berry, P., Spink, J., Sylvester-Bradley, R., Pickett, A., Sterling, M., Baker, C., Cameron, N., 2002. Lodging control through variety choice and management. In: HGCA Conference, Agronomic Intelligence: The Basis for Profitable Production, pp. 1-12.

Berry, P.M., Sterling, M., Mooney, S.J., 2006. Development of a model of lodging for barley. J. Agron. Crop Sci. 192 (2), 151-158.

Berry, P.M., White, C., Sterling, M., Baker, C.J., 2013. Development of a model of lodging risk in oilseed rape to enable integrated lodging control to reduce PGR use, CRD Project PS2146, August.

Board, S.S., National Research Council, 2007. Earth Science and Applications from Space: National Imperatives for the Next Decade and Beyond. National Academies Press.

Bock, C.H., Poole, G.H., Parker, P.E., Gottwald, T.R., 2010. Plant disease severity estimated visually, by digital photography and image analysis, and by hyperspectral imaging. Crit. Rev. Plant Sci. 29 (2), 59-107.

Boschetti, M., Busetto, L., Manfron, G., Laborte, A., Asilo, S., Pazhanivelan, S., Nelson, A., 2017. PhenoRice: a method for automatic extraction of spatio-temporal information on rice crops using satellite data time series. Remote Sens. Environ. 194, 347-365.

Bouman, B.A.M., 1991. Crop parameter estimation from ground-based X-band (3-cm wave) radar backscattering data. Remote Sens. Environ. 37 (3), 193-205.

Bouman, B.A., Hoekman, D.H., 1993. Multi-temporal, multi-frequency radar measurements of agricultural crops during the Agriscatt-88 campaign in The Netherlands. Remote Sens. 14 (8), 1595-1614.

Bouman, B.A.M., van Kasteren, H.W.J., 1990a. Ground-based X-band (3-cm wave) radar backscattering of agricultural crops. I. Sugar beet and potato; backscattering and crop growth. Remote Sens. Environ. 34 (2), 93-105.

Bouman, B.A.M., van Kasteren, H.W.J., 1990b. Ground-based X-Band (3 cm wave) radar backscattering of agricultural crops. 2. wheat, barley and oats; the impact of canopy structure. Remote Sens. Environ. 34 (2), 107-118.

Branson, M., 2011. Using conservation agriculture and precision agriculture to improve a farming system. In: Rainfed Farming Systems. Springer, Dordrecht, pp. 875-900.

Brown, S.C., Quegan, S., Morrison, K., Bennett, J.C., Cookmartin, G., 2003. High-resolution measurements of scattering in wheat canopies-Implications for crop parameter retrieval. IEEE Trans. Geosci. Remote Sens. 41 (7), 1602-1610.

Brune, P.F., Baumgarten, A., Mckay, S.J., Technow, F., Podhiny, J.J., 2017. A biomechanical model for maize root lodging. Plant Soil 422 (1-2), 397-408.

Burkart, A., Aasen, H., Alonso, L., Menz, G., Bareth, G., Rascher, U., 2015. Angular dependency of hyperspectral measurements over wheat characterized by a novel UAV based goniometer. Remote Sens. 7 (1), 725-746.

Caldicott, J.J.B., 1966. The interaction of Cycocel 2-chloroethyltrimethylammonium chloride and nitrogen top dressing on the growth, lodging and yield of wheat. In: Proc. 8th Brighton Weed Control Conf., November, vol. 1. pp. 229-239.

Caldicott, J.B., Nuttall, A.M., 1968. The effects of combined applications of chlormequat and herbicides to cereals. In: Proc. 9th Br. Weed Control Conf, pp. 244-248.

Caldicott, J.J.B., Nuttall, A.M., 1979. A method for the assessment of lodging in cereal crops. J. Natl. Inst. Agric. Bot. 15, 88-91.

Campbell, J.B., Wynne, R.H., 2011. Introduction to Remote Sensing. Guilford Press.

Campos-Taberner, M., García-Haro, F.J., Camps-Valls, G., Grau-Muedra, G., Nutini, F., Crema, A., Boschetti, M., 2016. Multitemporal and multiresolution leaf area index retrieval for operational local rice crop monitoring. Remote Sens. Environ. 187, 102-118.

Chakraborty, M., Manjunath, K.R., Panigrahy, S., Kundu, N., Parihar, J.S., 2005. Rice crop parameter retrieval using multi-temporal, multi-incidence angle Radarsat SAR data. ISPRS J. Photogramm. 59 (5), 310-322.

Chalmers, A.G., Dyer, C.J., Sylvester-Bradley, R., 1998. Effects of nitrogen fertilizer on the grain yield and quality of winter oats. J. Agric. Sci. Cambridge 131, 395-407.

Chapman, S.C., Merz, T., Chan, A., Jackway, P., Hrabar, S., Dreccer, M.F., Holland, E., Zheng, B., Jun Ling, T., Jimenez-Berni, J., 2014. Pheno-copter: a low-altitude, autonomous remote-sensing robotic helicopter for high-throughput field-based phenotyping. Agron. J. 4 (2), 279-301.

Chauhan, S., Srivastava, H.S., Patel, P., 2018. Wheat crop biophysical parameters retrieval using hybrid-polarized RISAT-1 SAR data. Remote Sens. Environ. 216, 28-43.

Chen, J., Gu, S., Shen, M., Tang, Y., Matsushita, B., 2009. Estimating aboveground biomass of grassland having a high canopy cover: an exploratory analysis of in situ hyperspectral data. Int. J. Remote Sens. 30 (24), 6497-6517.

Chen, J., Li, H., Han, Y., 2016. Potential of RADARSAT-2 data on identifying sugarcane lodging caused by typhoon. In: Fifth International Conference on AgroGeoinformatics (Agro-Geoinformatics). IEEE, pp. 1-6.

Chu, L., Huang, C., Liu, Q.S., Liu, G.H., 2016. Estimation of winter wheat phenology under the influence of cumulative temperature and soil salinity in the Yellow River Delta, China, using MODIS time-series data. Int. J. Remote Sens. 37 (10), 2211-2232.

Chu, T., Starek, M.J., Brewer, M.J., Murray, S.C., Pruter, L.S., 2017. Assessing lodging severity over an experimental maize (Zea mays L.) field using UAS images. Remote
Sens. 9 (9), 923.

Cleland, E.E., Chuine, I., Menzel, A., Mooney, H.A., Schwartz, M.D., 2007. Shifting plant phenology in response to global change. Trends Ecol. Evol. 22 (7), 357-365.

Clevers, J. G., 1986. Application of remote sensing to agricultural field trials (Doctoral dissertation, Clevers)

Colomina, I., de la Tecnologia, P.M., 2008. Towards a new paradigm for high-resolution low-cost photogrammetry and remote sensing. In: ISPRS XXI Congress, Beijing China, July, pp. 1201-1206.

Constantinescu, C., Herbei, M., Manea, D., Sala, F., 2017. Analysis of some deficiencies in crops of wheat and barley based on terrestrial and aerial images. Res. J. Agric. Sci. 49 (1).

Coquil, B., 2004. FARMSTAR a fully operational system for crop management from satellite imagery. In: Mulla, D.J. (Ed.), Proceedings of the 7TH International Conference on Precision Agriculture Conference,. The Precision Agriculture Center, University of Minneapolis, St Paul, MN, USA (on CD-ROM).

Crook, M.J., Ennos, A.R., 1993. The mechanics of root lodging in winter wheat. Triticum Aestivum L. 44 (265), 1219-1224.

Crook, M.J., Ennos, A.R., 1994. Stem and root characteristics associated with lodging resistance in four winter wheat cultivars. J. Agric. Sci. 123 (2), 167.

Crook, M.J., Ennos, A.R., 1995. The effect of nitrogen and growth-Regulators on stem and root characteristics associated with lodging in 2 cultivars of winter-wheat. J. Exp. Bot. 46 (289), 931-938.

Cushnie, J.L., 1987. The interactive effect of spatial resolution and degree of internal variability within land-cover types on classification accuracies. Int. J. Remote Sens. 8 (1), 15-29.

Dente, L., Satalino, G., Mattia, F., Rinaldi, M., 2008. Assimilation of leaf area index derived from ASAR and MERIS data into CERES-Wheat model to map wheat yield. Remote Sens. Environ. 112 (4), 1395-1407.

Dickinson, J.L., Shirk, J., Bonter, D., Bonney, R., Crain, R.L., Martin, J., Phillips, T., Purcell, K., 2012. The current state of citizen science as a tool for ecological research and public engagement. Front. Ecol. Environ. 10 (6), 291-297.

Doraiswamy, P.C., Hatfield, J.L., Jackson, T.J., Akhmedov, B., Prueger, J., Stern, A., 2004. Crop condition and yield simulations using Landsat and MODIS. Remote Sens. Environ. 92 (4), 548-559.

Du, M., Noguchi, N., 2017. Monitoring of wheat growth status and mapping of wheat yield's within-field spatial variations using color images acquired from UAV-camera system. Remote Sens. 9 (3), 289.

Easson, D.L., White, E.M., Pickles, S.J., 1993. The effects of weather, seed rate and cultivar on lodging and yield in winter wheat. J. Agric. Sci. 121 (2), 145-156.

Eitel, J.U., Magney, T.S., Vierling, L.A., Greaves, H.E., Zheng, G., 2016. An automated method to quantify crop height and calibrate satellite-derived biomass using hypertemporal lidar. Remote Sens. Environ. 187, 414-422.

El Debaby, A.E., Ibrahim, K.E., Saad, A.M.M., El Salhy, T.S., 1994. Wheat lodging and growth characters as affected by some agricultural practices (No. 96-110472. CIMMYT).

Erdle, K., Mistele, B., Schmidhalter, U., 2011. Comparison of active and passive spectral sensors in discriminating biomass parameters and nitrogen status in wheat cultivars. Field Crops Res. 124 (1), 74-84.

Erten, E., Lopez-Sanchez, J.M., Yuzugullu, O., Hajnsek, I., 2016. Retrieval of agricultural crop height from space: a comparison of SAR techniques. Remote Sens. Environ. 187, $130-144$.

Everitt, J.H., Escobar, D.E., Villarreal, R., Noriega, J.R., Davis, M.R., 1991. Airborne video systems for agricultural assessment. Remote Sens. Environ. 35 (2-3), 231-242.

Ezequiel, C.A.F., Cua, M., Libatique, N.C., Tangonan, G.L., Alampay, R., Labuguen, R.T., Favila, C.M., Honrado, J.L.E., Canos, V., Devaney, C., Loreto, A.B., 2014. UAV aerial imaging applications for post-disaster assessment, environmental management and infrastructure development. In: International Conference on Unmanned Aircraft Systems (ICUAS), May. IEEE, pp. 274-283.

Fang, H., Liang, S., Hoogenboom, G., Teasdale, J., Cavigelli, M., 2008. Corn-yield estimation through assimilation of remotely sensed data into the CSM-CERES-Maize model. Int. J. Remote Sens. 29 (10), 3011-3032.

Fang, H., Liang, S., Kuusk, A., 2003. Retrieving leaf area index using a genetic algorithm with a canopy radiative transfer model. Remote Sens. Environ. 85 (3), 257-270.

Fischer, R.A., Stapper, M., 1987. Lodging effects on high-yielding crops of irrigated semidwarf wheat. Field Crops Res. 17 (3-4), 245-258.

Fitch, B.W., Walraven, R.L., Bradley, D.E., 1984. Polarization of light reflected from grain crops during the heading growth stage. Remote Sens. Environ. 15 (3), 263-268.

Freeman, A., Villasenor, J., Klein, J.D., Hoogeboom, P., Groot, J., 1994. On the use of multi-frequency and polarimetric radar backscatter features for classification of agricultural crops. Int. J. Remote Sens. 15 (9), 1799-1812.

Fritz, S., McCallum, I., Schill, C., Perger, C., Grillmayer, R., Achard, F., Kraxner, F., Obersteiner, M., 2009. Geo-Wiki.Org: The use of crowdsourcing to improve global. Land Cover. Remote Sens. 1 (3), 2072-4292.

Funk, C., Budde, M.E., 2009. Phenologically-tuned MODIS NDVI-based production anomaly estimates for Zimbabwe. Remote Sens. Environ. 113 (1), 115-125.

Gao, F., Morisette, J.T., Wolfe, R.E., Ederer, G., Pedelty, J., Masuoka, E., Myneni, R., Tan, B., Nightingale, J., 2008. An algorithm to produce temporally and spatially continuous MODIS-LAI time series. IEEE Geosci. Remote Sens. Lett. 5 (1), 60-64.

Gao, S., Niu, Z., Huang, N., Hou, X., 2013. Estimating the Leaf Area Index, height and biomass of maize using HJ-1 and RADARSAT-2. Int. J. Appl. Earth Obs. Geoinf. 24, 1-8.

Gerten, D.M., Wiese, M.V., 1987. Microcomputer-assisted video image analysis of lodging in winter wheat. Photogramm. Eng. Remote Sens. 53 (1), 83-88.

Gherboudj, I., Magagi, R., Berg, A.A., Toth, B., 2011. Soil moisture retrieval over agricultural fields from multi-polarized and multi-angular RADARSAT-2 SAR data. Remote Sens. Environ. 115 (1), 33-43. 
Green, C.F., Ivins, J.D., 1985. Time of sowing and the yield of winter wheat. J. Agric. Sci. Cambridge 104 (1), 235-238.

Han, D., Yang, H., Yang, G., Qiu, C., 2017. Monitoring model of corn lodging based on Sentinel-1 radar image. In: SAR in Big Data Era: Models, Methods and Applications (BIGSARDATA). IEEE, pp. 1-5.

Hanley, F., Jarvis, R., Whitear, J.D., 1961. The effects of time of ploughing and time of drilling on the development and yield of the winter wheat crop following a clover ley. J. Agric. Sci. Cambridge 56, 119-125.

He, L., Song, X., Feng, W., Guo, B.B., Zhang, Y.S., Wang, Y.H., Wang, C.Y., Guo, T.C., 2016. Improved remote sensing of leaf nitrogen concentration in winter wheat using multi-angular hyperspectral data. Remote Sens. Environ. 174, 122-133.

Holman, F.H., Riche, A.B., Michalski, A., Castle, M., Wooster, M.J., Hawkesford, M.J., 2016. High throughput field phenotyping of wheat plant height and growth rate in field plot trials using UAV based remote sensing. Remote Sens. 8 (12), 1031.

Holzman, M.E., Carmona, F., Rivas, R., Niclòs, R., 2018. Early assessment of crop yield from remotely sensed water stress and solar radiation data. ISPRS J. Photogramm. 145, 297-308.

Hong, S., Lakshmi, V., Small, E.E., 2007. Relationship between vegetation biophysical properties and surface temperature using multisensor satellite data. J. Clim. 20 (22), 5593-5606.

Hosoi, F., Nakai, Y., Omasa, K., 2009. Estimating the leaf inclination angle distribution of the wheat canopy using a portable scanning lidar. J. Agric. Meteorol. 65 (3), 297-302.

Hosoi, F., Omasa, K., 2012. Estimation of vertical plant area density profiles in a rice canopy at different growth stages by high-resolution portable scanning lidar with a lightweight mirror. ISPRS J. Photogramm. Remote Sens. 74, 11-19.

Huang, Y., Thomson, S.J., Ortiz, B.V., Reddy, K.N., Ding, W., Zablotowicz, R.M., Bright, J.R., 2010. Airborne remote sensing assessment of the damage to cotton caused by spray drift from aerially applied glyphosate through spray deposition measurements. Biosyst. Eng. 107 (3), 212-220.

Hunt, E.R., Cavigelli, M., Daughtry, C.S., Mcmurtrey, J.E., Walthall, C.L., 2005. Evaluation of digital photography from model aircraft for remote sensing of crop biomass and nitrogen status. Precis. Agric. 6 (4), 359-378.

Inoue, Y., 2003. Synergy of remote sensing and modeling for estimating ecophysiological processes in plant production. Plant Prod. Sci. 6 (1), 3-16.

Inoue, Y., Guérif, M., Baret, F., Skidmore, A., Gitelson, A., Schlerf, M., et al., 2016. Simple and robust methods for remote sensing of canopy chlorophyll content: a comparative analysis of hyperspectral data for different types of vegetation. Plant, Cell Environ. 39 (12), 2609-2623.

Islam, M.S., Peng, S., Visperas, R.M., Ereful, N., Bhuiya, M.S.U., Julfiquar, A.W., 2007. Lodging-related morphological traits of hybrid rice in a tropical irrigated ecosystem. Field Crops Res. 101 (2), 240-248.

Jackson, R.D., 1986. Remote sensing of biotic and abiotic plant stress. Annu. Rev. Phytopathol. 24 (1), 265-287.

Jain, M., Srivastava, A.K., Joon, R.K., McDonald, A., Royal, K., Lisaius, M.C., Lobell, D.B., 2016. Mapping smallholder wheat yields and sowing dates using micro-satellite data. Remote Sens. 8 (10), 860.

Jones, H.G., 2013. Plants and Microclimate: A Quantitative Approach to Environmental Plant Physiology. Cambridge University Press.

Keller, M., Schimel, D.S., Hargrove, W.W., Hoffman, F.M., 2008. A continental strategy for the national ecological observatory network. Front. Ecol. Environ. 6 (5), 282-284.

Kirby, E.J.M., 1967. The effect of plant density upon the growth and yield of barley. J. Agric. Sci. 68 (3), 317-324.

Kirby, E.J.M., Appleyard, M., Fellowes, G., 1985. Variation in development of wheat and barley in response to sowing date and variety. J. Agric. Sci. 104 (2), 383-396.

Kong, E., Liu, D., Guo, X., Yang, W., Sun, J., Li, X., Zhan, K., Cui, D., Lin, J., Zhang, A., 2013. Anatomical and chemical characteristics associated with lodging resistance in wheat. Crop J. 1 (1), 43-49.

Lang, Y.Z., Yang, X.D., Wang, M.E., Zhu, Q.S., 2012. Effects of lodging at different filling stages on rice yield and grain quality. Rice Sci. 19 (4), 315-319.

Laude, H.H., Pauli, A.W., 1956. Influence of lodging on yield and other characters in winter wheat. Agron. J. 48 (10), 452-455.

Lee, F.N., Rush, M.C., 1983. Rice sheath blight: a major rice disease. Plant Dis. 67, 829-832.

Lemaire, G., Jeuffroy, M.H., Gastal, F., 2008. Diagnosis tool for plant and crop N status in vegetative stage: Theory and practices for crop N management. Eur. J. Agron. 28 (4), 614-624.

Li, F., Miao, Y., Hennig, S.D., Gnyp, M.L., Chen, X., Jia, L., Bareth, G., 2010. Evaluating hyperspectral vegetation indices for estimating nitrogen concentration of winter wheat at different growth stages. Precis. Agric. 11 (4), 335-357.

Liu, Z., Li, C., Wang, Y., Huang, W., Ding, X., Zhou, B., Wu, H., Wang, D., Shi, J., 2011. Comparison of spectral indices and principal component analysis for differentiating lodged rice crop from normal ones. In: International Conference on Computer and Computing Technologies in Agriculture. Springer, Berlin, Heidelberg, pp. 84-92.

Liu, H.Y., Yang, G.J., Zhu, H.C., 2014. The extraction of wheat lodging area in UAV's image used spectral and texture features. Appl. Mech. Mater. 651-653, 2390-2393.

Maes, W.H., Steppe, K., 2012. Estimating evapotranspiration and drought stress with ground-based thermal remote sensing in agriculture: a review. J. Exp. Bot. 63 (13) 4671-4712.

Mahlein, A.K., Rumpf, T., Welke, P., Dehne, H.W., Plümer, L., Steiner, U., Oerke, E.C., 2013. Development of spectral indices for detecting and identifying plant diseases. Remote Sens. Environ. 128, 21-30.

Manfron, G., Delmotte, S., Busetto, L., Hossard, L., Ranghetti, L., Brivio, P.A., Boschetti, M., 2017. Estimating inter-annual variability in winter wheat sowing dates from satellite time series in Camargue, France. Int. J. Appl. Earth Obs. Geoinf. 57, 190-201.
Marinho, E., Vancutsem, C., Fasbender, D., Kayitakire, F., Pini, G., Pekel, J.F., 2014. From remotely sensed vegetation onset to sowing dates: Aggregating pixel-level detections into village-level sowing probabilities. Remote Sens. 6 (11), 10947-10965.

Martinez-Vazquez, P., Sterling, M., 2011. Predicting wheat lodging at large scales Biosyst. Eng. 109 (4), 326-337.

McNairn, H., Brisco, B., 2004. The application of C-band polarimetric SAR for agriculture: a review. Can. J. Remote Sens. 30 (3), 525-542.

Mi, C., Zhang, X., Li, S., Yang, J., Zhu, D., Yang, Y., 2011. Assessment of environment lodging stress for maize using fuzzy synthetic evaluation. Math. Comput. Model. 54 (3), 1053-1060.

Milford, G.F.J., Penny, A., Prew, R.D., Darby, R.J., Todd, A.D., 1993. Effects of previous crop, sowing date, and winter and spring applications of nitrogen on the growth, nitrogen uptake and yield of winter wheat. J. Agric. Sci. 121 (1), 1-12.

Moran, M.S., Inoue, Y., Barnes, E.M., 1997. Opportunities and limitations for image-based remote sensing in precision crop management. Remote Sens. Environ. 61 (3), 319-346.

Murakami, T., Yui, M., Amaha, K., 2012. Canopy height measurement by photogrammetric analysis of aerial images: application to buckwheat (Fagopyrum esculentum Moench) lodging evaluation. Comput. Electron. Agric. 89, 70-75.

Mutanga, O., Skidmore, A.K., 2004. Narrow band vegetation indices overcome the saturation problem in biomass estimation. Int. J. Remote Sens. 25 (19), 3999-4014.

Nebiker, S., Annen, A., Scherrer, M., Oesch, D., 2008. A light-weight multispectral sensor for micro UAV_-opportunities for very high resolution airborne remote sensing. Int. Arch. Photogram. Remote Sens. Spatial Inf. Sci. 37 (B1), 1193-1199.

Neenan, M., Spencer-Smith, J.L., 1975. An analysis of the problem of lodging with particular reference to wheat and barley. J. Agric. Sci. 85 (3), 495-507.

Neinavaz, E., Skidmore, A.K., Darvishzadeh, R., Groen, T.A., 2016. Retrieval of leaf area index in different plant species using thermal hyperspectral data. ISPRS J. Photogramm. 119, 390-401.

Niu, L., Feng, S., Ding, W., Li, G., 2016. Influence of speed and rainfall on large-scale wheat lodging from 2007 to 2014 in China. PloS One 11 (7), e0157677.

Norberg, O.S., Mason, S.C., Lowry, S.R., 1988. Ethephon influence on harvestable yield, grain quality, and lodging of corn. Agron. J. 80 (5), 768-772.

Ogden, R.T., Miller, C.E., Takezawa, K., Ninomiya, S., 2002. Functional regression in crop lodging assessment with digital images. J. Agric. Biol. Environ. Stat. 7 (3), 389-402.

Pacifici, F., Chini, M., Emery, W.J., 2009. A neural network approach using multiscale textural metrics from very high-resolution panchromatic imagery for urban land-use classification. Remote Sens. Environ. 113 (6), 1276-1292.

Patel, P., Srivastava, H.S., Panigrahy, S., Parihar, J.S., 2006. Comparative evaluation of the sensitivity of multi-polarized multi-frequency SAR backscatter to plant density. Int. J. Remote Sens. 27 (2), 293-305.

Pettorelli, N., Vik, J.O., Mysterud, A., Gaillard, J.M., Tucker, C.J., Stenseth, N.C., 2005. Using the satellite-derived NDVI to assess ecological responses to environmental change. Trends Ecol. Evol. 20 (9), 503-510.

Pinthus, M.J., 1974. Lodging in wheat, barley, and oats: the phenomenon, its causes, and preventive measures. Adv. Agron. 25 (C), 209-263.

Piñera-Chavez, F.J., Berry, P.M., Foulkes, M.J., Jesson, M.A., Reynolds, M.P., 2016. Avoiding lodging in irrigated spring wheat. I. Stem and root structural requirements. Field Crops Res. 196, 325-336.

Quang Duy, P., Hirano, M., Sagawa, S., Kuroda, E., 2004. Analysis of the dry matter production process related to yield and yield components of rice plants grown under the practice of nitrogen-free basal dressing accompanied with sparse planting density. Plant Prod. Sci. 7 (2), 155-164.

Rango, A., Laliberte, A., Herrick, J.E., Winters, C., Havstad, K., Steele, C., Browning, D., 2009. Unmanned aerial vehicle-based remote sensing for rangeland assessment, monitoring, and management. J. Appl. Remote Sens. 3 (1), 033542.

Sakamoto, T., Shibayama, M., Takada, E., Inoue, A., Morita, K., Takahashi, W., Miura, S., Kimura, A., 2010. Detecting seasonal changes in crop community structure using day and night digital images. Photogramm. Eng. Remote Sens. 76 (6), 713-726.

Sangoi, L., Gracietti, M.A., Rampazzo, C., Bianchetti, P., 2002. Response of Brazilian maize hybrids from different eras to changes in plant density. Field Crops Res. 79 (1), 39-51.

Schaepman, M.E., Ustin, S.L., Plaza, A.J., Painter, T.H., Verrelst, J., Liang, S., 2009. Earth system science related imaging spectroscopy-an assessment. Remote Sens. Environ. 113, S123-S137.

Setter, T.L., Laureles, E.V., Mazaredo, A.M., 1997. Lodging reduces yield of rice by selfshading and reductions in canopy photosynthesis. Field Crops Res. 49 (2-3), 95-106.

Sims, D.A., Gamon, J.A., 2002. Relationships between leaf pigment content and spectral reflectance across a wide range of species, leaf structures and developmental stages. Remote Sens. Environ. 81 (2), 337-354.

Sisler, W.W., Olsen, P.J., 1951. A study of methods of influencing lodging in barley and the effect of lodging upon yield and certain quality characteristics. Sci. Agric. 31, $177-186$.

Sorenson, P.T., Small, C., Tappert, M.C., Quideau, S.A., Drozdowski, B., Underwood, A., Janz, A., 2017. Monitoring organic carbon, total nitrogen, and $\mathrm{pH}$ for reclaimed soils using field reflectance spectroscopy. Can. J. Soil Sci. 97 (2), 241-248.

Spink, J.H., Whaley, J.M., Semere, T., Wade, A.P., Sparkes, D.L., Foulkes, M.J., 2000. Prediction of optimum plant population in winter wheat. HGCA Research Project No. 234. Home-Grown Cereals Authority, London.

Sposaro, M.M., Berry, P.M., Sterling, M., Hall, A.J., Chimenti, C.A., 2010. Modelling root and stem lodging in sunflower. Field Crops Res. 119 (1), 125-134.

Stanca, A.M., Jenkins, G., Hanson, P.R., 1979. Varietal responses in spring barley to natural and artificial lodging and to a growth regulator. J. Agric. Sci. Cambridge 93, 449-456.

Sterling, M., Baker, C.J., Berry, P.M., Wade, A., 2003. An experimental investigation of the lodging of wheat. Agric. For. Meteorol. 119 (3-4), 149-165. 
Stroppiana, D., Villa, P., Sona, G., Ronchetti, G., Candiani, G., Pepe, M., Busetto, L., Migliazzi, M., Boschetti, M., 2018. Early season weed mapping in rice crops using multi-spectral UAV data. Int. J. Remote Sens. 1-21.

Sullivan, D.G., Fulton, J.P., Shaw, J.N., Bland, G., 2007. Evaluating the sensitivity of an unmanned thermal infrared aerial system to detect water stress in a cotton canopy. Trans. ASABE 50 (6), 1963-1969.

Sylvester-Bradley, R., Scott, R.K., Wright, C.E., 1990. Physiology in the production and improvement of cereals. Physiology in the Production and Improvement of Cereals 18.

Thenkabail, P.S., Smith, R.B., De Pauw, E., 2000. Hyperspectral vegetation indices and their relationships with agricultural crop characteristics. Remote Sens. Environ. 71 (2), 158-182.

Thorp, K.R., Steward, B.L., Kaleita, A.L., Batchelor, W.D., 2007. Using aerial hyperspec tral remote sensing imagery to estimate corn plant stand density. Trans. ASABE 51 (1), 311-320.

Tripathi, S.C., Sayre, K.D., Kaul, J.N., Narang, R.S., 2003. Growth and morphology of spring wheat (Triticum aestivum L.) culms and their association with lodging: effects of genotypes, N levels and ethephon. Field Crops Res. 84 (3), 271-290.

Ulaby, F.T., Allen, C.T., Eger Iii, G., Kanemasu, E., 1984. Relating the microwave backscattering coefficient to leaf area index. Remote Sens. Environ. 14 (1-3), 113-133.

Ulaby, F.T., Moore, R.K., Fung, A.K., 1986. Microwave Remote Sensing: Active and Passive. Artech House, Boston, MA.

Van Roekel, R.J., Coulter, J.A., 2011. Agronomic responses of corn to planting date and plant density. Agron. J. 103 (5), 1414-1422.

Verrelst, J., Rivera, J.P., Veroustraete, F., Muñoz-Marí, J., Clevers, J.G., Camps-Valls, G., Moreno, J., 2015. Experimental Sentinel-2 LAI estimation using parametric, nonparametric and physical retrieval methods-a comparison. ISPRS J. Photogramm. 108, 260-272.

Webster, J.R., Jackson, L.F., 1993. Management practices to reduce lodging and maximise grain yield and protein content of fall-sown irrigated hard red spring wheat. Field Crops Res. 33, 240-259.

Weishampel, J.F., Drake, J.B., Cooper, A., Blair, J.B., Hofton, M., 2007. Forest canopy recovery from the 1938 hurricane and subsequent salvage damage measured with airborne LiDAR. Remote Sens. Environ. 109 (2), 142-153.

White, E.M., 1991. Response of winter barley cultivars to nitrogen and a plant growth regulator in relation to lodging. J. Agric. Sci. 116 (2), 191-200.

Wu, W., Ma, B.L., 2016. A new method for assessing plant lodging and the impact of management options on lodging in canola crop production. Sci. Rep. 6, 31890.

Yang, H., Chen, E., Li, Z., Zhao, C., Yang, G., Pignatti, S., Casa, R., Zhao, L., 2015. Wheat lodging monitoring using polarimetric index from RADARSAT-2 data. Int. J. Appl. Earth Obs. Geoinf. 34, 157-166.

Yang, M., Huang, K., Kuo, Y., Tsai, H.P., Lin, L., 2017. Spatial and spectral hybrid image classification for rice lodging assessment through UAV imagery. Remote Sens. 9 (6), 583.

Zadoks, J.C., Chang, T.T., Konzak, C.F., 1974. A decimal code for the growth stages of cereals. Weed Res. 14 (6), 415-421.

Zhang, X., Friedl, M.A., Schaaf, C.B., Strahler, A.H., Hodges, J.C., Gao, F., Reed, B.C., Huete, A., 2003. Monitoring vegetation phenology using MODIS. Remote Sens. Environ. 84 (3), 471-475.

Zhang, C., Walters, D., Kovacs, J.M., 2014. Applications of low altitude remote sensing in agriculture upon farmers' requests-a case study in northeastern Ontario, Canada. PloS One 9 (11), e112894.

Zhao, L., Yang, J., Li, P., Shi, L., Zhang, L., 2017. Characterizing lodging damage in wheat and canola using radarsat-2 polarimetric SAR Data. Remote Sens. Lett. 8 (7), 667-675.

Zhu, G., Li, G., Wang, D., Yuan, S., Wang, F., 2016. Changes in the lodging-related traits along with rice genetic improvement in China. Plos One 11 (7), e0160104. 